Of the three major $A P O E$ allelic variants, $\varepsilon 2, \varepsilon 3$ and $\varepsilon 4, A P O E^{*} \varepsilon 4$ is associated with an increased risk ${ }^{4,5}$ and $A P O E^{*} \varepsilon 2$ is associated with a decreased risk ${ }^{6,7}$ of $\mathrm{AD}$ relative to the common $A P O E^{*} \varepsilon 3$ allele. Carrying one $A P O E^{*} \varepsilon 4$ allele increases the risk of late-onset $\mathrm{AD}$ 3-4-fold, and carrying two alleles increases the risk 9-15-fold ${ }^{6,8,9}$. Among individuals with $\mathrm{AD}, A P O E^{*} \varepsilon 4$ is also associated with lower age of disease onset (Box 1 $)^{4,10}$. Mounting evidence suggests that the APOE4 protein isoform drives amyloid pathology and impairs multiple aspects of normal brain function, thereby increasing the risk of $\mathrm{AD}^{11}$ (Table 1). Studies have also shed light on the associations between $A P O E$ genotype and tau-mediated neurodegeneration ${ }^{12}$, the risk of dementia with Lewy bodies (DLB) ${ }^{13-15}$, Parkinson disease dementia (PDD) ${ }^{15-18}$ and the degree of TAR DNA-binding protein 43 (TDP43) pathology in the brains of individuals with $\mathrm{AD}^{19-21}$. In addition, advances in disease modelling and molecular profiling technology have provided insights into the role of APOE in AD pathogenesis at the molecular, cellular and organism level.

In light of these findings, in this Review we describe the emerging link between $A P O E$ genotype and pathogenic proteins found in the brains of individuals with AD. We summarize recent progress in understanding the mechanisms by which different APOE isoforms contribute to or counteract $\mathrm{AD}$ pathogenesis via $\mathrm{A} \beta$-dependent and $\mathrm{A} \beta$-independent pathways. Finally, we discuss opportunities and strategies for developing APOE-targeted $\mathrm{AD}$ therapies in the future.

\section{Biology of APOE}

Human APOE is a $34 \mathrm{kDa}$ glycoprotein ${ }^{22}$ that is composed of 299 amino acids after cleavage of the 18-amino-acid signal peptide. In the CNS, APOE is abundantly expressed in astrocytes, microglia, vascular mural cells and choroid plexus cells, and to a lesser extent in stressed neurons ${ }^{23,24}$. Once APOE has been secreted from the cells, the cell surface ATPbinding cassette transporters $\mathrm{ABCA} 1^{25}$ and $\mathrm{ABCG} 1^{26}$ transfer cholesterol and phospholipids to nascent APOE to form lipoprotein particles. The size and density of APOE lipoprotein particles in the cerebrospinal fluid (CSF) are similar to those of $\mathrm{HDL}^{27}$. APOE plays a critical role in redistributing cholesterol and other lipids to neurons through binding to cell-surface APOE receptors. The LDL receptor (LDLR) family members, including LDLR and LDLR-related protein 1 (LRP1), are major APOE receptors involved in APOEmediated lipid metabolism. APOE has two main functional regions (FIG. 1): the receptorbinding region in the amino-terminal domain and the lipid-binding region in the carboxyterminal domain ${ }^{28,29}$.

Computer-assisted modelling has been performed to examine the conformational changes in APOE that potentially occur on lipid binding. Structural modelling of human APOE3 was accomplished using data on APOE from the Protein Data Bank ${ }^{30-37}$. The modelling technique has been well documented ${ }^{38-44}$ and enables composite protein structures to be built from multiple structural templates. The resulting lipid-free and lipid-bound structures are shown in FIG. $1^{45-48}$. The structures show that the lipid-binding region (residues 244272) of APOE interacts directly with the lipid particle. Lipid binding to APOE increases the accessibility of the receptor-binding region (residues 136-150), thereby enabling cellular lipid delivery. The structural changes to APOE that are predicted to take place on lipid 
binding are consistent with those documented in the existing structural literature for this protein $^{30,31,34,35,37,49-54}$.

The APOE isoforms encoded by the three corresponding gene alleles differ from one another only at positions 112 and 158 (APOE2: Cys112, Cys158; APOE3: Cys112, Arg158; APOE4: Arg112, Arg158). However, these single amino acid polymorphisms substantially alter the structure and function of APOE, thereby modulating its binding properties with regard to both lipids and receptors. For example, the binding of APOE2 to LDLR is more than 50 times weaker than the binding of APOE3 or APOE4 to this receptor ${ }^{55}$. In the periphery, the relatively low affinity of APOE2 for LDLR impairs the clearance of triglyceride-rich lipoprotein remnant particles and, as a consequence, APOE2 contributes to the onset of type III hyperlipoproteinaemia ${ }^{22,56}$. By contrast, enhanced binding of APOE4 to VLDL particles, as compared with the other APOE isoforms ${ }^{55}$, impairs lipolytic processing of VLDL in the periphery; thus, APOE4 is associated with pro-atherogenic changes in lipoprotein distribution ${ }^{56}$.

In addition to their role in lipid homeostasis in the periphery, APOE isoforms differentially modulate multiple pathways in the brain, including lipid transport, synaptic integrity and plasticity, glucose metabolism and cerebrovascular function. However, the correlation between the structure of individual APOE isoforms and their modulation of these pathways in the brain is less clear than for their actions on peripheral lipid metabolism. Possible mechanisms by which structural differences between APOE isoforms could modulate these brain pathways include differences in protein conformation, post-translational modification, lipoprotein preference and binding affinity for receptors ${ }^{29}$.

Studies have also shed light on the potential role of plasma APOE in brain homeostasis. Synaptic dysfunction in Apoe-knockout mice can be partially restored, and cognition improved, by genetic restoration of peripheral $\mathrm{APOE}^{57}$. These effects occur despite the presence of the blood-brain barrier (BBB), which blocks APOE influx from the periphery. The relative ratio of APOE4 to APOE3 in plasma positively correlates with the loss of regional grey matter volume and abnormal cerebral glucose metabolism in cognitively healthy $A P O E^{*} \varepsilon 3 / \varepsilon 4$ carriers $^{58}$, linking the isoform composition of plasma APOE to structural and metabolic changes of the brain. Therefore, plasma APOE is a potential determinant of brain structure and function.

In $A P O E^{*} \varepsilon 3 / \varepsilon 4$ individuals, the APOE4:APOE3 ratio is $>1$ in the brain and CSF but $<1$ in the plasma ${ }^{59,60}$, suggesting that the metabolic pathways of APOE isoforms differ between the CNS and plasma. Thus, further studies exploring the similarities and differences in APOE metabolism between the CNS and periphery, and the functional crosstalk between brain and plasma APOE, would aid a better understanding of the impact of APOE isoforms on brain physiology.

\section{APOE4 and $A \beta$ pathology}

Although evidence from clinical and pathological studies shows a link between $A P O E$ genotype and multiple proteinopathies, including those involving tau, a-synuclein and 
TDP43, the best-established association is between $A P O E$ genotype and A $\beta$. Pathological studies of post-mortem brain tissue from patients with $\mathrm{AD}$ have found that $A P O E^{*} \varepsilon 4$ exacerbates the intra-neuronal accumulation of $A \beta^{61}$, plaque deposition in the brain parenchyma $^{62-65}$, formation of neurotoxic $\mathrm{A} \beta$ oligomers ${ }^{66}$ and the severity of cerebral amyloid angiopathy (CAA) ${ }^{67,68}$. By contrast, $A P O E^{*} \varepsilon 2$ is associated with reduced numbers of neuritic plaques ${ }^{69}$ but somewhat increased risks of CAA and CAA-related intracranial haemorrhage ${ }^{70-73}$.

Imaging and CSF biomarker studies have shown that $A P O E^{*} \varepsilon 4$ is consistently associated with greater $A \beta$ deposition in the brains of cognitively healthy elderly individuals ${ }^{74-78}$, individuals with mild cognitive impairment (MCI) ${ }^{79}$ and individuals with $\mathrm{AD}^{80}$. A longitudinal study also showed that $A P O E^{*} \varepsilon 4$ carriers exhibit increased $\mathrm{A} \beta$ deposition in the cortex compared with $A P O E^{*} \varepsilon 4$ non-carriers ${ }^{81}$. Of note, $A P O E^{*} \varepsilon 4$ is associated with an increased rate of longitudinal $A \beta$ accumulation among cognitively healthy individuals who are amyloid-negative, whereas no differences in rates of $\mathrm{A} \beta$ deposition are observed among amyloid-positive individuals with different $A P O E$ genotypes $^{82}$. Assuming that longitudinal $A \beta$ accumulation represents an early phase of amyloid deposition in amyloid-negative individuals and a later phase in amyloid-positive individuals, these results suggest that the effect of $A P O E^{*} \varepsilon 4$ on $\mathrm{A} \beta$ metabolism and aggregation is most pronounced during the initiation phase of $\mathrm{A} \beta$ deposition. By contrast, in cross-sectional studies, $A P O E^{*} \varepsilon 2$ was found to be associated with reduced brain $\mathrm{A} \beta$ deposition in cognitively healthy elderly people $77,83,84$ and individuals with $\mathrm{MCI}^{85}$, particularly those without an $A P O E^{*} \varepsilon 4$ allele. $A P O E^{*} \varepsilon 2$ is also protective against longitudinal $\mathrm{A} \beta$ accumulation, especially among individuals without amyloid deposition ${ }^{82}$. Together, multiple layers of evidence indicate that the $A P O E$ genotype, in particular the presence of $A P O E^{*} \varepsilon 4$, modulates amyloid pathology in the brain.

The effect of APOE4 in driving amyloid pathology is likely to outweigh the protective effect of APOE2 (FIG. 2, Table 2) ${ }^{85}$, as $A P O E^{*} \varepsilon 2 / \varepsilon 4$ and $A P O E^{*} \varepsilon 3 / \varepsilon 4$ individuals have comparable probabilities of exhibiting amyloid- $\beta(\mathrm{A} \beta)$ deposition on an amyloid-PET scan. In addition, among cognitively healthy individuals and people with MCI, the prevalence of amyloid pathology is higher in those with $A P O E^{*} \varepsilon 2 / \varepsilon 4$ than in those with $A P O E^{*} \varepsilon 3 / \varepsilon 3$. These findings indicate that APOE4 is a strong driver of $A \beta$ deposition irrespective of the presence of APOE2 or APOE3. Importantly, the pattern of estimated probabilities of amyloid positivity associated with different $A P O E$ genotypes is similar to that of $\mathrm{AD}$ risk $^{6,8,9}$ (Table 2), reinforcing the idea that APOE4 increases the risk of AD largely by causing earlier and more abundant amyloid pathology in the brain. Likewise, the presence of $A P O E^{*} \varepsilon 2$ might reduce $\mathrm{AD}$ risk by decreasing amyloid pathology, especially in the absence of $A P O E^{*} \varepsilon 4$. However, given that $A P O E^{*} \varepsilon 2$ is associated not only with intact cognition but also, paradoxically, with increased $\mathrm{AD}$ pathology ${ }^{86}$ in the oldest old population, the protective effect of $A P O E^{*} \varepsilon 2$ might also be mediated by $\mathrm{A} \beta$-independent mechanisms. Supporting this notion, $A P O E^{*} \varepsilon 2$ is associated with reduced cognitive decline during ageing even after adjustment for $\mathrm{A} \beta$ pathologies ${ }^{87}$. 


\section{A $\beta$ clearance.}

As $A \beta$ is continuously generated in the brain as a result of APP processing, efficient clearance is vital for preventing $A \beta$ accumulation and subsequent aggregation ${ }^{88}$. The clearance of soluble A $\beta$ from the brain interstitial fluid (ISF) occurs in an APOE isoformdependent manner with APOE4 less efficient than APOE2 or APOE $3^{89}$. In addition, deficiency of ABCA1, which lipidates APOE, decreases A $\beta$ clearance in APOE4-targeted replacement (TR) mice, in which murine Apoe is replaced by a specific allele of human $A P O E$, whereas no such effect is observed in APOE3-TR mice ${ }^{90}$. Thus, the isoform and lipidation status of APOE is likely to influence the overall efficiency of A $\beta$ clearance in the brain. Major pathways by which $A \beta$ is removed from the brain include clearance through the $\mathrm{BBB}$, cellular uptake and subsequent degradation, enzymatic degradation, clearance via ISF bulk flow, and CSF absorption into the circulatory and lymphatic systems ${ }^{88}$. The effects of individual APOE isoforms on each of these processes (FIG. 3) could contribute in a synergistic manner to variations in $\mathrm{A} \beta$ metabolism rates, in particular under pathogenic conditions.

The removal of $A \beta$ via transport through the BBB is mediated by APOE in an isoformdependent manner. An in vivo study showed that APOE2-A $\beta$ and APOE3-A $\beta$ complexes were cleared by both VLDLR and LRP1 at the BBB, whereas APOE4 binding to A $\beta$ switched the clearance pathway of $A \beta$ at the BBB from LRP1 to the VLDL receptor $(\mathrm{VLDLR})^{91}$. As VLDLR mediates the internalization of APOE-A $\beta$ complex at a slower rate than LRP1, redirection of the clearance pathway for the APOE4-A $\beta$ complex might contribute to the slower clearance of $A \beta$ at the BBB, when compared with APOE2-A $\beta$ and APOE3-A $\beta$ complexes ${ }^{91}$. Consistent with the findings in vivo, a study utilizing a tissue engineering approach to generate a 3D model of human brain blood vessels showed that APOE4 was less efficient than APOE2 at promoting A $\beta$ transport across vessel walls ${ }^{92}$. Furthermore, an in vitro study showed that clearance of $A \beta$ aggregates by BBB-associated pericytes was impaired in the presence of astrocyte-derived APOE4 compared with APOE $3^{93}$. The precise mechanisms by which APOE isoforms interact with $A \beta$ receptors to mediate $A \beta$ efflux from or influx into the brain require further investigation.

Cellular uptake and subsequent degradation of $\mathrm{A} \beta$ by glial cells represents a crucial $\mathrm{A} \beta$ clearance pathway in the brain. Human iPSC-derived astrocytes that are homozygous for $A P O E^{*} \varepsilon 4$ show impaired uptake of $\mathrm{A} \beta_{1-42}$ in vitro compared with $A P O E^{*} \varepsilon$-homozygous $\mathrm{iPSCs}^{94}$. A study using mouse brain slices indicated that astrocyte-mediated degradation of A $\beta$ occurs through a mechanism that is dependent on both APOE and LRP1, suggesting that APOE is essential for receptor-mediated A $\beta$ uptake by astrocytes ${ }^{95}$. However, another study showed that downregulation of LDLR reduced $A \beta$ uptake, whereas upregulation of LDLR enhanced both the uptake and clearance of $A \beta$ in astrocytes, independently of $\mathrm{APOE}^{96}$. A more recent study showed that the interaction between APOE and A $\beta$ under physiological conditions is minimal, and that APOE might not be required for the cellular clearance of $\mathrm{A} \beta$ in astrocytes ${ }^{97}$. Instead, APOE competes with A $\beta$ for the LRP1-dependent cellular uptake pathway, thereby blocking $\sim 50 \%$ of the total $\mathrm{A} \beta$ cellular clearance by astrocytes in vitro ${ }^{97}$. Therefore, receptor-mediated internalization of $A \beta$ in astrocytes might at least be partially 
affected by the presence of different APOE isoforms and APOE receptors, with APOE4 impairing the uptake of $A \beta$ by these cells.

Cellular uptake and degradation of $A \beta$ by microglia is also differentially influenced by the various APOE isoforms. Degradation of $A \beta$ peptides by neprilysin within microglia is markedly facilitated in the presence of APOE, with APOE4 being less efficient at promoting the degradation of soluble $\mathrm{A} \beta$ than APOE2 and APOE $3^{98}$. In addition, APOE-mediated cholesterol efflux facilitates the delivery of $A \beta$ to lysosomes and increases the efficiency of intracellular $\mathrm{A} \beta$ degradation in microglia ${ }^{99}$. The clearance of extracellular $\mathrm{A} \beta$ has been found to be impaired in human iPSC-derived microglia-like cells expressing $A P O E^{*} \mathcal{E} 4$ compared with those expressing $A P O E^{*} 3^{94}$.

Studies have also investigated the effects of APOE isoforms on other clearance pathways, including perivascular drainage and proteolytic degradation of $A \beta$ by $A \beta$-degrading proteases (A $\beta$-DPs). A wide array of A $\beta$-DPs, including neprilysin and insulin degrading enzyme (IDE), determine $A \beta$ levels in the brain ${ }^{100}$. Expression of neprilysin in both brain parenchyma and vasculature and that of IDE in hippocampus are significantly lower in postmortem brains from individuals with at least one copy of $A P O E^{*} \varepsilon 4$ than in those from individuals without $A P O E^{*} \varepsilon 4^{101,102}$. The perivascular drainage pathway has a major role in ISF bulk-flow clearance of $A \beta^{103}$. In a study that examined this pathway, after intracerebral injections of $A \beta_{1-40}$, aggregation of $A \beta_{1-40}$ in the peri-arterial drainage pathway was observed in APOE4-TR mice but not in APOE3-TR mice ${ }^{104}$. Thus, the clearance of A $\beta$ mediated by proteolytic degradation and perivascular drainage pathways seems to be impaired by the presence of APOE4.

The influence of APOE isoforms on the glymphatic clearance of $A \beta^{105}$ is less clear. In one study, APOE derived from the choroid plexus and CSF was shown to be delivered into the brain via the glymphatic fluid transporting system in an APOE isoform-dependent manner ${ }^{106}$, although the relevance of these findings to disease needs to be further investigated.

\section{Formation of $A \beta$ fibrils.}

$A \beta$ aggregation occurs when $A \beta$ is over-produced and/or inefficiently cleared. The formation of $\mathrm{A} \beta$ fibrils, a major component of amyloid plaques, follows three kinetic stages: a lag phase, a growth phase and a plateau phase ${ }^{107}$. Although the effects of APOE on the formation of $A \beta$ fibrils are inconsistent in vitro ${ }^{29,108}$, in vivo studies have shown a crucial role for APOE in the initial seeding stage of $A \beta$ deposition. Through a novel approach involving conditional expression of different APOE isoforms in a mouse model of amyloid pathology, astrocytic overexpression of APOE4, but not APOE3, during the initial A $\beta$ seeding stage was found to exacerbate amyloid pathology. However, expression of APOE4 or APOE3 during the period of rapid plaque growth had no effect on $\mathrm{A} \beta$ deposition ${ }^{109}$. In another study published in parallel, reduction of APOE expression by antisense oligonucleotide (ASO) treatment beginning at postnatal day 0 (A $\beta$ seeding stage) led to a significant reduction in amyloid pathology in amyloid mouse models that were homozygous for $A P O E^{*} \varepsilon 3$ or $A P O E^{*} 4^{110}$. By contrast, ASO treatment beginning at the onset of amyloid deposition did not change the overall plaque load ${ }^{110}$. These in vivo results align 
with the notion that APOE, and in particular APOE4, promotes the formation of A $\beta$ fibrils by accelerating the initial seeding or nucleation of $A \beta$ peptides (FIG. 3).

\section{A $\beta$ production.}

Given that the generation of $A \beta$ peptide from amyloid precursor protein (APP) represents a pivotal event in $\mathrm{AD}$ pathogenesis ${ }^{111}$, researchers have sought to identify the role of APOE in this process. A study published in 2017 found that HEK293 cell-derived APOE induced $A P P$ transcription and $\mathrm{A} \beta$ production in human embryonic stem cell-derived and induced pluripotent stem cell (iPSC)-derived neurons. The effects were isoform-dependent, with APOE4 stimulating $A \beta$ production more potently than other isoforms ${ }^{112}$. A $\beta$ secretion is significantly higher in human iPSC-derived neurons carrying $A P O E^{*} \varepsilon 4$ than in those with $A P O E^{*} \mathcal{E} 3$, probably as a result of increased APP transcription or processing ${ }^{94,113}$. However, transcriptomic analysis of cortical tissue from APOE-TR mice did not reveal the transcriptional regulation of $A p p$ associated with APOE4 ${ }^{114}$. Furthermore, in mouse models of amyloid pathology that expressed human APOE, no APOE isoform-dependent differences in the amount of APP fragment C99 or $\beta$-secretase activity were observed, suggesting that amyloidogenic processing of APP does not vary in the presence of different APOE isoforms in vivo ${ }^{89}$. Species-dependent (human versus mouse) differences in APOE isoform-regulated $\mathrm{A} \beta$ production ${ }^{113}$ may have contributed to these conflicting results.

\section{APOE in AD pathogenesis: beyond amyloid}

$A P O E$ allele effects have also been implicated in proteinopathies characterized by tau, $\mathrm{a}$ synuclein, and TDP43 pathology in the brains of individuals with AD. In addition, emerging evidence suggests that APOE can modulate tau-mediated neurodegeneration as well as microglial homeostasis, synaptic integrity, lipid transport, glucose metabolism and cerebrovascular function (FIG. 4). In this section, we discuss the disease relevance of these findings within the context of $A P O E$ genotype and its association with the risk of AD.

\section{Tau, a-synuclein and TDP43 proteinopathies.}

Findings suggest that $A P O E$ alleles exert an effect on neurodegenerative diseases marked by the aggregation of tau, a microtubule-associated protein encoded by the MAPT gene ${ }^{115}$. Individuals with primary tauopathies, such as progressive supranuclear palsy (PSP) and corticobasal degeneration (CBD) $)^{115,116}$, exhibit tau but not amyloid pathology. AD, though characterized by extensive tau pathology, is considered a secondary tauopathy as the tau pathology is accompanied by earlier development of amyloid pathology. Of note, postmortem brains from individuals carrying two $A P O E^{*} \varepsilon 4$ alleles have more tau aggregates than those carrying either one or no $A P O E^{*} \varepsilon 4$ alleles when $\mathrm{A} \beta$ pathology is present ${ }^{65}$, but no such association is observed in brains without $A \beta^{117,118}$. Moreover, among patients with PSP, the presence of concomitant amyloid pathology is associated with an increased likelihood of carrying $A P O E^{*} \varepsilon 4^{119}$. Thus, $A P O E^{*} \varepsilon 4$ is likely to be a risk factor for amyloid pathology but not necessarily for tau burden in primary tauopathies ${ }^{119,120}$. Interestingly, although $A P O E^{*} \varepsilon 2$ is protective in the setting of $\mathrm{AD}$, in the absence of amyloid pathology it has been implicated as a risk factor for tau-related neurodegeneration ${ }^{121}$. A study showed that $A P O E^{*} \varepsilon 2$ was associated with increased risk 
and greater severity of tau pathology in patients with $\mathrm{PSP}^{122}$. Taken together, these results indicate that the effects of $A P O E$ alleles on tauopathies are influenced by the presence of amyloid pathology.

The pathological aggregation of tau strongly correlates with patterns of neurodegeneration and clinical manifestations in $\mathrm{AD}^{123-126}$. Studies have shown that neuron-specific overexpression of APOE4 increases tau phosphorylation in mice ${ }^{127}$. Subsequently, Shi et al. crossed the Tau ${ }^{\mathrm{P} 301 \mathrm{~S}}$ transgenic mouse model, which overexpresses human tau containing the frontotemporal dementia-linked Pro301Ser mutation, with human APOE-TR mice. $\mathrm{Tau}^{\mathrm{P} 301 \mathrm{~S}}$-APOE4-TR mice developed markedly more brain atrophy and neuroinflammation

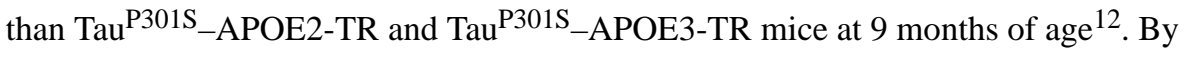
contrast, Zhao et al. introduced tau with another frontotemporal dementia-linked mutation, Pro301Leu, to APOE-TR mice via viral delivery, and found more severe tau pathology and behavioural deficits at 6 months of age in Tau ${ }^{\mathrm{P} 301 \mathrm{~L}}$-APOE2-TR mice than in $\mathrm{Tau}^{\mathrm{P} 301 \mathrm{~L}_{-}}$ APOE3-TR and Tau ${ }^{\text {P301L_APOE4-TR mice }}{ }^{122}$. These seemingly contradictory results are likely to be a result of differences in the experimental model systems that the two groups used. Furthermore, Shi et al. measured tau-mediated neurodegeneration, whereas Zhao et al. focused on tau pathology.

In addition to the findings from mouse models, human iPSC-derived $A P O E^{*} \varepsilon 4$-expressing neurons have higher levels of tau phosphorylation than neurons expressing $A P O E^{*} \varepsilon 3^{113}$. Taken together, these results suggest that APOE influences tau pathology and tau-mediated neuronal toxicity in an isoform-dependent manner. Understanding the relevance of these findings to different neurodegenerative diseases with tauopathy as either a primary or concurrent pathology will require further studies using models that are more relevant to the specific disease conditions.

$A P O E^{*} \varepsilon 4$ is also a genetic risk factor for $\mathrm{DLB}^{13-15}$ and $\mathrm{PDD}^{15-18}$. These conditions are both classified as synucleinopathies, a spectrum of neurodegenerative disorders that also includes $\mathrm{PD}^{128,129}$ and is characterized by the presence of hallmark accumulations of $\mathrm{a}$ synuclein, termed Lewy bodies, within neuronal cell bodies ${ }^{130,131}$. Patients with DLB or PDD often have some degree of concomitant AD-type pathology 132,133 , and 30-40\% of individuals with $\mathrm{AD}$ also present with Lewy bodies ${ }^{134}$. Therefore, determining whether $A P O E^{*} \varepsilon 4$ contributes to a-synuclein pathology through an A $\beta$-dependent mechanism, similar to that proposed for tau pathology in the amyloid cascade hypothesis ${ }^{135}$, or through an $\mathrm{A} \beta$-independent mechanism ${ }^{136}$ remains challenging. However, a study published in 2018 demonstrated that in individuals with Lewy body disease, $A P O E^{*} \mathcal{E} 4$ was associated with increased a-synuclein pathology irrespective of the degree of AD pathology ${ }^{137}$, suggesting that $A P O E^{*} \varepsilon 4$ impacts the severity of a-synuclein pathology independently of tau and $\mathrm{A} \beta$. Of note, the gene encoding LDLR-related protein 10 (LRP10), which is thought to play a role in the metabolism of APOE lipoproteins ${ }^{138}$ and the trafficking of $\mathrm{APP}^{139}$, is associated with the development of inherited forms of DLB and $\mathrm{PD}^{140}$.

$A P O E^{*} \varepsilon 4$ might also directly increase the risk of TDP43 pathology in the brains of people with AD. TDP43 proteinopathy is a core pathological hallmark of amyotrophic lateral sclerosis and of frontotemporal lobar degeneration with TDP43 pathology ${ }^{141}$, and often 
coexists with $\mathrm{AD}$ pathology. Of note, $A P O E^{*} \varepsilon 4$ is associated with the presence of comorbid TDP43 proteinopathy in the brains of individuals with $\mathrm{AD}^{19}$, as well as the severity of TDP43 proteinopathy, even after adjusting for the presence of $A \beta$, tau and Lewy body pathologies ${ }^{21}$. These observations suggest that a direct association between $A P O E^{*} \varepsilon 4$ and TDP43 proteinopathy exists in AD. A study published in 2018 confirmed that $A P O E^{*} \varepsilon 4$ is associated with TDP43 pathology independently of A $\beta$ in the brains of individuals with $\mathrm{AD}^{20}$.

In summary, $A P O E$ allele-specific effects on tau and a-synuclein proteinopathies, and on TDP43 pathology in the brains of individuals with $A D$, have been identified; however, the relevance of these findings to AD risk and disease progression is currently unclear. Further studies addressing the associations between APOE isoforms and these pathogenic proteins, using a model that reflects disease-specific conditions, should increase our understanding of APOE pathobiology within the context of AD.

\section{Neuroinflammation.}

Evidence suggests that APOE has an important role in regulating the innate immune response to amyloid pathology and neurodegeneration. Microglia play a central role in the immune response in the brain, highlighted by the abundant reactive microgliosis surrounding $\mathrm{A} \beta$ plaques in post-mortem brain tissue from individuals with $\mathrm{AD}^{142}$. These diseaseassociated microglia (DAM) ${ }^{143-145}$, also referred to as a microglial neurodegenerative (MGnD) phenotype ${ }^{146}$, have a conserved transcriptional signature across mouse models of AD. $A P O E$ is among these DAM-associated genes, as $A P O E$ expression by microglia is upregulated in association with ageing and amyloid and tau pathology ${ }^{14}$. By contrast, APOE deficiency diminishes the DAM signature in AD mouse models ${ }^{146,147}$, highlighting the crucial role of APOE in regulating DAM phenotypes.

The various APOE isoforms seem to modulate microglial functions differently in AD pathogenesis ${ }^{148}$. Human iPSC-derived microglia-like cells carrying $A P O E^{*} \mathcal{E} 4$ exhibit altered morphologies and reduced levels of $\mathrm{A} \beta$ phagocytosis when compared with those carrying $A P O E^{*} \varepsilon 3^{94}$. APOE4 also increases microglial reactivity against $\mathrm{A} \beta$ plaques in a mouse model of amyloid pathology ${ }^{149}$. Furthermore, APOE4 boosts microglial proinflammatory activation and neurodegeneration in a tau transgenic mouse model ${ }^{12}$. One suggestion is that the specific lipid composition of the APOE4 lipoprotein affects lipid raft structures on microglial cell membranes to induce a stronger DAM phenotype, which exacerbates $A \beta$ or tau pathogenesis and neurodegeneration ${ }^{150}$.

APOE is an endogenous ligand of triggering receptor expressed on myeloid cells 2 (TREM2) ${ }^{151-153}$, a cell surface receptor expressed exclusively by microglia in the brain. A rare coding variant of TREM2 is associated with increased risk of $\mathrm{AD}$, with an effect size comparable to that of $A P O E^{*} \varepsilon 4^{154,155}$. Furthermore, TREM2 is likely to mediate the APOE-dependent molecular signatures in microglia ${ }^{146,150,156}$. As such, the APOE-TREM2 pathway might contribute to $\mathrm{AD}$ pathogenesis through the modulation of microglial homeostasis ${ }^{157,158}$. 
A study published in 2019 demonstrated that amyloid plaque seeding was increased in the absence of functional TREM2, both in animal models and in individuals with $\mathrm{AD}^{159}$. Lack of TREM2 was also associated with a reduction in plaque-associated APOE. Of note, levels of plaque-associated APOE were substantially reduced on microglial depletion in a mouse model of amyloid pathology, indicating that microglia represent a prominent source of amyloid plaque-associated APOE. Thus, microglial APOE seems to be induced in a TREM2-dependent manner, suggesting an important association of APOE with TREM2 in the context of $\mathrm{AD}$ pathogenesis.

\section{Synaptic function.}

Increasing evidence indicates that the presence of $A P O E^{*} \varepsilon 4$ is associated with increased synaptic degeneration ${ }^{160}$ and synaptic accumulation of $A \beta$ oligomers ${ }^{66}$, along with reductions in dendritic density ${ }^{161}$, plasticity ${ }^{160}$ and numbers of glutamate receptors ${ }^{162}$, in the brains of individuals with AD. In addition, the levels of the synaptic markers synaptophysin, syntaxin 1 and postsynaptic density protein 95 (PSD95) are reduced in the brains of $A P O E^{*} \varepsilon 4$ carriers, and levels of PSD95 are increased in the brains of $A P O E^{*} \varepsilon 2$ carriers ${ }^{163}$. Consistent with findings from post-mortem human brains, reduced expression of synaptic proteins ${ }^{164,165}$, reduced dendritic spine density and length ${ }^{166}$, and impaired synaptic transmission ${ }^{167,168}$ have all been observed in APOE4-TR mice when compared with APOE3-TR mice. In addition, APOE4 reduces neuronal surface expression of the LDLR family member APOER2 (also known as LRP8), along with NMDA and AMPA receptors, by sequestering them in the intracellular endosomal compartments ${ }^{169}$, leading to suppression of reelin-mediated synaptic transmission. Therefore, the isoform-dependent effect of APOE on the intracellular trafficking of lipoprotein and glutamate receptors represents a potential mechanism by which APOE4 can impair synaptic plasticity ${ }^{170}$. Furthermore, hippocampal neurogenesis and hilar GABAergic neurotransmission are impaired in mice carrying $A P O E^{*} \varepsilon 4^{171-173}$.

Collectively, these results suggest that APOE4 is either less efficient at maintaining synaptic integrity and neurogenesis than other AOPE isoforms or has a toxic effect ${ }^{113}$ on these spinerelated and synapse-related pathways. Given that synaptic loss strongly correlates with cognitive decline in $\mathrm{AD}$, the impact of APOE4 on synaptic function and neurogenesis might combine with other APOE4-mediated pathways and AD pathology to contribute to the earlier onset of symptoms.

\section{Lipid transport.}

Several lipid transport-related properties of APOE have been shown to be isoformdependent. Although in vitro studies using cell systems with limited relevance to human brain physiology such as HEK293 cells and immortalized mouse astrocytes generated inconsistent results ${ }^{174,175}$, a more recent study using iPSC-derived astrocytes showed that APOE4 is less lipidated than APOE3, which could potentially diminish the neurotrophic function of $\mathrm{APOE} 4{ }^{176}$. In addition, in the CSF, APOE particles are larger in $A P O E^{*} \varepsilon 2 / \varepsilon 3$ individuals and smaller in both $A P O E^{*} \varepsilon 3 / \varepsilon 4$ and $A P O E^{*} \varepsilon 4 / \varepsilon 4$ individuals than in $A P O E^{*} \varepsilon 3 / \varepsilon 3$ individuals ${ }^{177}$. Furthermore, cholesterol efflux capacity is impaired in the CSF of individuals who are homozygous for $A P O E^{*} \varepsilon 4^{178}$. The amount of poorly lipidated APOE 
in the CSF is higher in $\mathrm{APOE}^{*} \varepsilon 4$ carriers than in $\mathrm{APOE}^{*} \varepsilon 4$ non-carriers ${ }^{179}$. Overall, the APOE isoform effects on the APOE-lipid interaction support a loss-of-function effect of $A P O E^{*} \varepsilon 4$, with APOE4 being less efficient than APOE2 or APOE3 at transporting lipids to neurons.

The overall lipid-transporting capacity of APOE could also be affected by the amount of this molecule within the brain ${ }^{180}$. In mice, the quantity of APOE in $\mathrm{CSF}^{181,182}$ ISF $^{183}$ and brain parenchyma ${ }^{182}$ shows an isoform-dependent gradient, with APOE2 being the most abundant and APOE4 the least abundant of the three isoforms. By contrast, studies utilizing a mass spectrometry-based approach in young control individuals (aged 22-60 years, average 34.5 \pm 10.3 years ${ }^{60}$, cognitively healthy people (aged $43-80$ years, average 61 years) and patients with AD (aged 60-94 years, average 78 years) ${ }^{59}$ found no isoform-dependent differences in APOE levels in the CSF. However, one of the studies found that in a cohort of A $\beta$-positive individuals composed of both cognitively healthy individuals and patients with $\mathrm{MCI}, \mathrm{APOE}$ levels in the CSF were significantly lower in $A P O E^{*} \varepsilon 4$ carriers than in noncarriers $^{60}$. Thus, the presence of $\mathrm{A} \beta$ in $A P O E^{*} \varepsilon 4$ carriers might further exacerbate APOE4mediated loss of neuroprotective function by decreasing the amount of APOE4 available to transport lipids to neurons.

\section{Glucose metabolism and insulin signalling.}

Several studies have highlighted the need to consider the $A P O E^{*} \varepsilon 4$ genotype when assessing the role of glucose metabolism and insulin signalling in AD. Cerebral glucose hypometabolism is an early biomarker of $\mathrm{AD}$ and exists in pre-symptomatic individuals long before the clinical onset of $\mathrm{AD}^{184-187}$. Altered levels of insulin, insulin receptors and insulin signalling are observed in the brain of individuals with $\mathrm{AD}$ compared with cognitively healthy individuals ${ }^{188-190}$, and epidemiological studies have confirmed that diabetes and midlife insulin resistance are risk factors for $\mathrm{AD}^{191,192}$. Interestingly, the $A P O E^{*} \varepsilon 4$ genotype, independently of $\mathrm{A} \beta$, contributes to age-related reductions in cerebral glucose metabolism and insulin signalling ${ }^{193-197}$. In the brain areas frequently affected in AD, $A P O E^{*} \varepsilon 4$ carriers, both with and without dementia, have lower cerebral glucose metabolism than non-carriers ${ }^{195,197-203}$. Phase II clinical trials of an insulin nasal spray in individuals with $\mathrm{AD}$ have shown that the preventative effects of insulin on cognitive decline are modulated by $A P O E$ genotype status ${ }^{204-206}$. In the CSF, increased levels of insulin are associated with increased levels of total tau and phosphorylated tau among $A P O E^{*} \varepsilon 4$ noncarriers $^{207}$. Fasting plasma insulin levels and free fatty acid levels are also increased in $A_{P O E^{*} \varepsilon 4 \text { non-carriers }}{ }^{208}$.

Consistent with the clinical findings, preclinical studies using APOE-TR mice have also revealed that APOE isoforms differentially influence brain glucose metabolism and insulin signalling. Compared with APOE3-TR mice, APOE4-TR mice display downregulation of brain peroxisome proliferator-activated receptor $\gamma(\operatorname{PPAR} \gamma)$ and PPAR $\gamma$ coactivator 1 (PGC1a) signalling, which is involved in the regulation of glucose uptake and metabolism ${ }^{209}$. Following treatment with a high-fat diet, APOE4-TR mice show more profound cognitive impairment, reduced cerebral blood volume, decreased glucose uptake, and impaired insulin signalling compared with APOE3-TR mice ${ }^{194,210}$, providing additional 
evidence that human APOE isoforms differentially modulate brain bioenergetic metabolism. Furthermore, APOE4-TR mice exhibit impaired brain insulin signalling and insulin resistance compared with APOE3-TR mice in an age-dependent manner ${ }^{194}$. Importantly, APOE4 interacts with insulin receptors and traps them in the endosomes, thus impairing insulin receptor trafficking and related signalling ${ }^{194}$. APOE receptors are also involved in brain glucose metabolism and insulin signalling. Conditional deletion of the gene encoding a major APOE receptor, LRP1, in mouse forebrain neurons leads to impaired brain insulin signalling and a reduced capacity to metabolize glucose $\mathrm{e}^{211}$.

\section{Cerebrovascular integrity and function.}

$A P O E^{*} \mathcal{E} 4$ is a risk factor for vascular cognitive impairment ${ }^{212,213}$, suggesting a possible link between this allele and neurovascular unit dysfunction. Imaging studies have shown that the presence of $A P O E^{*} \varepsilon 4$ is associated with increased severity of white matter hyperintensities independently of AD diagnosis ${ }^{214,215}$. In cognitively healthy individuals, $A P O E^{*} \varepsilon 4$ carriers show a higher CSF:plasma albumin quotient than $A P O E^{*} \varepsilon 4$ noncarriers $^{216}$, suggesting that $\mathrm{BBB}$ integrity is disrupted in the carriers. $A P O E^{*} \varepsilon 4$ carrier status is also associated with accelerated pericyte degeneration and loss of BBB integrity in $\mathrm{AD}$, as observed in post-mortem brain tissue ${ }^{217}$. Thus, multiple layers of clinical evidence suggest a link between $A P O E^{*} \varepsilon 4$ and impaired cerebrovascular integrity and function, both in the presence and absence of AD pathology.

Consistent with these findings, reduced cerebral blood flow, vascular density and neurovascular coupling are observed in APOE4-TR mice compared with APOE2-TR and APOE3-TR mice ${ }^{218-220}$. Loss of BBB integrity has also been observed in APOE4-TR mice $^{218,219}$, although conflicting results have been obtained ${ }^{221}$. Another study showed that cerebral hypoperfusion, white matter damage and cognitive impairment induced by bilateral carotid artery stenosis are more severe in APOE4-TR mice than in APOE3-TR mice 220. Overall, these APOE isoform effects on cerebrovascular integrity and function suggest that APOE4 is less efficient than APOE2 or APOE3 at maintaining cerebrovascular homeostasis. Of note, analysis using data sets from the Alzheimer's Disease Neuroimaging Initiative $(\mathrm{ADNI})^{222}$, and a CSF biomarker study ${ }^{223}$ both indicated a role for vascular dysregulation in the early stages of the AD cascade. Thus, determining how the cerebrovascular effects of APOE4 drive AD pathogenesis could represent an important area for future studies.

The cerebrovascular contribution to cognitive decline and synaptic dysfunction probably combines with the accumulation of pathogenic proteins, such as $\mathrm{A} \beta^{224,225}$, in both a synergistic and an additive manner. Therefore, the role of cerebrovascular effects of APOE4 in $\mathrm{AD}$ pathogenesis needs to be investigated in the context of both $\mathrm{A} \beta$-dependent and $\mathrm{A} \beta$ independent mechanisms. Peripheral APOE4 might modulate cerebrovascular function by exerting direct actions on the endothelial cells ${ }^{226}$ that form the BBB, which exists as an interface between the CNS and the peripheral circulation. In addition, peripheral APOE4 could indirectly modulate the functions of brain endothelial cells and neurons through its effects on lipid metabolism, atherosclerosis and peripheral inflammation, perhaps acting synergistically with other vascular risk factors ${ }^{227}$. 
Perhaps surprisingly, $A P O E^{*} \varepsilon 2$ is associated with increased risk of CAA and CAA-related intracranial haemorrhage ${ }^{70-73}$ and severity of cerebral small vessel disease ${ }^{215,228}$ despite its protective effect against AD risk. However, the cerebrovascular effects of APOE2 remain relatively unexplored.

\section{APOE-targeted therapies for AD}

The current strategies for targeting of APOE to treat $\mathrm{AD}$ fall into three main categories: modulating APOE quantity and lipidation, targeting APOE structural properties and interactions with $\mathrm{A} \beta$, and targeting APOE receptors.

\section{Modulating APOE quantity and lipidation.}

As discussed above, APOE has crucial roles in lipid transport and maintenance of synaptic homeostasis. Therefore, AD-related pathways might be modulated by increasing the quantity and/or degree of lipidation of APOE. In particular, administration of agonists of the liver $\mathrm{X}$ receptor (LXR) and the retinoid $\mathrm{X}$ receptor (RXR) has been shown to positively regulate transcription and secretion of $\mathrm{APOE}^{229}$, reduce $\mathrm{A} \beta$ deposition ${ }^{98,230-233}$ and restore cognitive function $98,231,233,234$ in mouse models of amyloid pathology. Oral administration of the RXR agonist bexarotene reduced $\mathrm{A} \beta$ deposition and improved cognitive function in amyloid mouse models ${ }^{235}$, including those that also expressed human $A P O E^{*} \varepsilon 3$ and $A P O E^{*} 4^{236}$, and in APOE4-TR mice ${ }^{237}$. Bexarotene also seems to combat ageing-related loss of synaptic proteins in mice ${ }^{238}$. However, conflicting results with respect to the effects of bexarotene on amyloid pathology in mouse models have also been reported $236,239-241$. In addition, systemic adverse effects including liver toxicity are observed on bexarotene treatment in mice ${ }^{238,242}$.

Bexarotene treatment does not reduce amyloid burden in patients with $\mathrm{AD}^{243}$. Oral administration of bexarotene to healthy individuals induced a 25\% increase in CSF APOE levels but had no effect on CSF A $\beta$ metabolism ${ }^{244}$ and showed poor CNS penetration. The clinical utility of bexarotene as a drug for AD might also be hampered by systemic adverse effects, such as hypertriglyceridaemia ${ }^{243}$, which are mediated by the permissive action of the RXR-LXR heterodimer on target genes, leading to activation of specific metabolic pathways in the liver ${ }^{245}$. Therefore, the potential clinical application of bexarotene has major limitations. From the perspective of gaining insight into APOE-targeted therapeutic strategies, the extent to which these RXR and LXR treatment-related phenotypes are mediated by an increase in APOE lipidation remains unclear. High-throughput screening for APOE agonists using human astrocytes may help to identify APOE-inducing compounds with pharmacological actions that do not depend on the nuclear receptor-APOE axis ${ }^{246}$.

Studies utilizing virus-mediated gene transfer approaches have also provided insights into whether increasing the expression of APOE isoforms that are considered protective halts AD pathogenesis. Virus-mediated human $A P O E$ gene expression in mice has been shown to have APOE isoform-dependent effects on brain A $\beta$ pathology $y^{247-249}$ and APOE lipidation $^{250}$. Adeno-associated virus (AAV)-mediated expression of $A P O E^{*} \mathcal{E} 4$ in a mouse model of amyloid pathology exacerbated synaptic loss and $A \beta$ deposition, whereas expression of $A P O E^{*} \varepsilon 2$ in the same model caused a reduction in brain $\mathrm{A} \beta$ levels ${ }^{249}$. 
Consistent with this finding, $\mathrm{AAV}$-mediated delivery of $A P O E^{*} \varepsilon 2$ reduced $\mathrm{A} \beta$ deposition in two different amyloid mouse models, crossed with $A P O E^{*} \varepsilon 4$ knock-in mice ${ }^{248}$.

Furthermore, overexpression of $A P O E^{*} \varepsilon 4$ in APOE4-TR mice increased the levels of poorly lipidated APOE in the brain, whereas overexpression of $A P O E^{*} \varepsilon 2$ in these mice enhanced APOE lipidation ${ }^{250}$. Therefore, increasing the expression of $A P O E^{*} \varepsilon 2$, but not $A P O E^{*} \varepsilon 4$, might be beneficial with regard to increasing APOE lipidation and reducing A $\beta$ pathology.

The therapeutic potential of decreasing the expression levels of specific APOE isoforms in order to reduce $A \beta$ deposition has also been investigated in mouse models. Decreasing APOE expression by $A P O E$ haploinsufficiency in an amyloid mouse model carrying $A P O E^{*} \varepsilon 3$ or $A P O E^{*} \varepsilon 4$ led to a reduction in $\mathrm{A} \beta$ deposition, which was independent of APOE isoform ${ }^{251,252}$. Furthermore, a study published in 2017 showed that reduction of APOE expression by ASOs significantly decreased A $\beta$ pathology in an amyloid mouse model that was homozygous for $A P O E^{*} \varepsilon 3$ or $A P O E^{*} \varepsilon 4^{110}$. Thus, decreasing the levels of APOE3 and APOE4, particularly during the initial A $\beta$ seeding stage, may be beneficial.

Given that APOE4 is associated with reduced levels of lipid in the CNS ${ }^{179,253}$, which could contribute to the APOE4-mediated loss of neuroprotective function, the question of whether an increase in APOE lipidation can reduce A $\beta$ pathology has been investigated. Deletion of the gene encoding ABCA1, which lipidates APOE in the CNS, resulted in a decrease in APOE lipidation and an increase in $A \beta$ deposition in amyloid mouse models ${ }^{254,255}$. Conversely, overexpression of ABCA1 in an amyloid mouse model decreased A $\beta$ deposition - an effect that was probably mediated by an increase in APOE lipidation ${ }^{256}$. In addition, an $A b c a 1$ hemizygous knockout exacerbated memory deficits and $\mathrm{A} \beta$ deposition in an amyloid mouse model carrying human $A P O E^{*} \varepsilon 4$, but not in mice carrying $A P O E^{*} \varepsilon 3^{90}$. The exacerbation of $\mathrm{A} \beta$ pathology in the mice carrying $A P O E^{*} \varepsilon 4$ could have been attributable to an increase in the amount of poorly lipidated APOE4 in the absence of one allele of Abcal. Whether, and to what extent, increasing APOE4 lipidation is beneficial in the presence of $\mathrm{A} \beta$ pathology remains to be fully determined.

APOE-mediated plaque formation might also be targeted via APOE immunotherapy. Treatment with the anti-mouse APOE antibody HJ6.3 induced a significant reduction in A $\beta$ deposition in a mouse model of amyloid pathology that expressed murine $\mathrm{APOE}^{257,258}$. In another study, $\mathrm{A} \beta$ deposition was reduced in an $A P O E^{*} \mathcal{E} 4$-positive amyloid mouse model following treatment with an anti-human APOE antibody, HAE-4, which preferentially binds the non-lipidated, aggregated form of $\mathrm{APOE}^{259}$. By binding to aggregated APOE in A $\beta$ plaques, HAE-4 is likely to induce activation of plaque phagocytosis by microglia, thereby reducing A $\beta$ deposition. Importantly, peripheral administration of HJ6.3 or HAE-4 does not change the total amount of APOE in plasma and brain parenchyma ${ }^{257-259}$. Thus, the targeting of APOE that is specifically associated with amyloid plaques is an attractive approach that would have minimal impact on the physiological function of APOE.

Treatment with peptides that mimic the structural and biological properties of native APOE reduces $A \beta$ deposition ${ }^{260,261}$, tau hyperphosphorylation ${ }^{262}$ and glial activation ${ }^{260-262}$ in mouse models of amyloid pathology. However, the effects of these peptides on $A \beta$ 
deposition and other AD-related pathologies in the context of human APOE isoforms have not been fully determined.

\section{Targeting APOE structural properties and $A \beta$ interaction.}

The pathological conformation of APOE4 is proposed to result from an interaction between its amino-terminal and carboxy-terminal domains ${ }^{263,264,265}$, and the use of small molecules to block this interaction has been explored in vitro $264,266,267$. The APOE4 structure corrector $\mathrm{PH} 002$, at a final concentration of $100 \mathrm{nM}$ in the culture medium, was shown to decrease APOE4 fragmentation and reduce the effects of APOE4 on A $\beta$ production, tau phosphorylation and GABAergic neuron degeneration in human iPSC-derived neurons ${ }^{113}$. Targeting the abnormal biophysical properties of APOE4 represents a potential therapeutic approach; however, the efficacy of this approach in vivo, in the context of human APOE isoforms and amyloid pathology, remains to be investigated.

Conversion of the APOE4 amino acid sequence into that of APOE3 or APOE2 seems to be a more straightforward approach to modulate the pathobiology of APOE4. Conversion of $A P O E^{*} \mathcal{E} 4$ to $A P O E^{*} \mathcal{E} 3$ by gene editing considerably alters cellular phenotypes ${ }^{94,113}$. Reductions in APOE fragmentation, A $\beta$ production, tau phosphorylation and GABAergic neuron degeneration are observed in iPSC-derived neurons when $A P O E^{*} \varepsilon 4$ is converted to $A P O E^{*} \varepsilon$ 3, suggesting that the detrimental effect of APOE4 could be abolished by gene editing ${ }^{113}$. Similarly, converting $A P O E^{*} \varepsilon 4$ to $A P O E^{*} \mathcal{E} 3$ attenuates several AD-related phenotypes in glial cells and organoids: this intervention enhances the ability of glial cells to endocytose extracellular $A \beta$ and significantly reduces the amount of $A \beta$ deposition in organoids after 6 months of culture ${ }^{94}$. Despite these promising in vitro findings, the in vivo feasibility and clinical translatability of this therapeutic concept remain to be determined.

Inhibition of the APOE-A $\beta$ interaction by the synthetic peptide $A \beta 12-28 \mathrm{P}$, which is homologous to the APOE binding site on the full-length $\mathrm{A} \beta$ molecule, reduced $\mathrm{A} \beta$ deposition ${ }^{268-270}$ and insoluble tau accumulation ${ }^{270}$ in AD mouse models, and intraneuronal $A \beta$ accumulation ${ }^{271}$ in primary hippocampal neurons. In addition, treatment with $A \beta 12-28 \mathrm{P}$ decreased brain $\mathrm{A} \beta$ accumulation, co-deposition of APOE within $\mathrm{A} \beta$ plaques and neuritic degeneration in amyloid mouse models with APOE2-TR and APOE4-TR backgrounds ${ }^{272}$. Therefore, blocking APOE-mediated facilitation of $A \beta$ assembly and/or deposition with a synthetic peptide seems to be beneficial in reducing $A \beta$ pathology, irrespective of APOE isoforms.

\section{Targeting APOE receptors.}

Given that clearance of A $\beta$ in the brain is partially mediated by APOE receptors, including LDLR and LRP1 ${ }^{28,29,273}$, increasing the expression of these receptors is a potential therapeutic strategy to reduce $A \beta$ pathology. In mouse models of amyloid pathology, $L d l r$ deficiency is associated with increased A $\beta$ deposition ${ }^{274,275}$, whereas overexpression of $L d l r$ leads to enhanced $A \beta$ clearance and decreased $A \beta$ deposition ${ }^{276}$. Conditional knockout of Lrp1 in neurons ${ }^{277}$, astrocytes ${ }^{278}$ and vascular smooth muscle cells ${ }^{279}$ led to increased A $\beta$ deposition in amyloid mouse models. Furthermore, treatment of animal models with compounds $^{280}$ that have been clinically explored for AD therapy, including fluvastatin ${ }^{281}$, 
decreases $\mathrm{A} \beta$ deposition and/or enhances $\mathrm{A} \beta$ clearance, probably by increasing Lrp1 expression. Whether these APOE receptor-related effects are mediated by APOE remains to be elucidated.

\section{Challenges and considerations.}

As with any attempts to target proteins that have essential physiological functions, a major challenge for APOE-targeted therapy is to minimize potential adverse effects on APOEdependent brain homeostasis and systemic physiology. One individual with an ablative homozygous $A P O E$ frameshift mutation did not exhibit substantial neurocognitive deficits at the age of 40 years $^{282}$. However, the impact of APOE deficiency on brain physiology in the context of ageing and AD development has not been documented. Thus, it will be crucial to monitor the effects of modulating APOE levels not only on AD pathogenesis, but also on brain physiology at different stages of AD development. The potential impact of APOEtargeted therapy on peripheral lipid metabolism and related physiology should also be considered. For example, modulating the amount of APOE or the expression of APOE receptors in the periphery could increase the risk of hyperlipidaemia, atherosclerosis and cardiovascular events, owing to impaired lipoprotein metabolism. Although increasing APOE2 levels in the brain might be beneficial, long-term expression of APOE2 could increase the risk of CAA, CAA-related intracerebral haemorrhage ${ }^{70-73}$ and perhaps primary tauopathy ${ }^{122}$.

These adverse effects could be managed by optimizing the treatment strategy for each $A P O E$ genotype, taking into consideration the treatment duration, the therapeutic window, and the specific biochemical properties and in vivo distribution of the pathogenic forms of APOE. Furthermore, the identification of APOE downstream effectors ${ }^{219}$ that modulate AD pathogenesis could provide therapeutic options with a limited impact on APOE-related physiology. Finally, the development and integration of novel technologies, such as targeted in vivo gene editing and more efficient drug delivery methods, could accelerate the clinical translation of APOE-targeted therapeutic concepts that have been uncovered in basic studies.

\section{Conclusions}

Strong evidence suggests that human APOE isoforms modulate AD pathogenesis primarily through their differential effects on A $\beta$ clearance and aggregation. However, APOE isoforms also differentially affect multiple pathways that are not necessarily dependent on $A \beta$, with APOE4 exhibiting either a gain of toxic function or a loss of physiological function. Associations between APOE isoforms and tau-mediated neurodegeneration, and the risk of multiple neurodegenerative proteinopathies found in the brains of individuals with $\mathrm{AD}$, are also recognized. Furthermore, a growing body of evidence links APOE with TREM2, highlighting the crucial role of APOE in the innate immune response in the brain.

To elucidate the precise pathological mechanism by which the $A P O E$ polymorphism determines the risk of AD (Table 1), several important yet underappreciated aspects of APOE pathobiology need to be determined. These aspects include the structure-function relationships for the different APOE isoforms, the impact of peripheral APOE on brain neurobiology and pathobiology, $\mathrm{A} \beta$-dependent and independent protective pathways 
activated by APOE2, similarities and differences in the role of APOE in late-onset and earlyonset $\mathrm{AD}$ (Box 2), sex-APOE genotype interactions (Box 3), and the role of APOE in immune responses and cerebrovascular pathways. As APOE is expressed by multiple cell types in the brain and periphery, the specific contributions of cell-autonomous versus cellnon-autonomous effects of APOE at different stages of AD development will also need to be investigated, perhaps using conditional mouse models and human cerebral organoids ${ }^{283}$, combined with human studies. Finally, a precision medicine approach based on $A P O E$ genotype status could facilitate the development of different AD treatment strategies (Box 4, FIG. 5). Establishment of APOE-based therapeutics is a considerable challenge; however, the targeting of APOE and its pathogenic interconnections offers great promise for the prevention and/or treatment of AD.

\section{Acknowledgements}

Support for work conducted in the authors' laboratory was provided by the National Institutes of Health (NIH), the Cure Alzheimer's Fund, the BrightFocus Foundation, the Alzheimer's Association, the American Heart Association, the MetLife Foundation for Medical Awards Program, and the Mayo Foundation for Medical Education and Research. The authors also thank C. Stetler for critical reading and editing of the manuscript.

\section{References}

1. Lambert JC et al. Meta-analysis of 74,046 individuals identifies 11 new susceptibility loci for Alzheimer's disease. Nat. Genet 45, 1452-1458, (2013). [PubMed: 24162737]

2. Assoc A. s. 2018 Alzheimer's disease facts and figures. Alzheimers Dement. 14, 367-425, (2018).

3. Serrano-Pozo A, Frosch MP, Masliah E \& Hyman BT Neuropathological alterations in Alzheimer disease. Cold Spring Harb. Perspect. Med 1, a006189, (2011). [PubMed: 22229116]

4. Corder EH et al. Gene dose of apolipoprotein E type 4 allele and the risk of Alzheimer's disease in late onset families. Science 261, 921-923, (1993). [PubMed: 8346443]

5. Saunders AM et al. Association of apolipoprotein E allele epsilon 4 with late-onset familial and sporadic Alzheimer's disease. Neurology 43, 1467-1472, (1993). [PubMed: 8350998]

6. Farrer LA et al. Effects of age, sex, and ethnicity on the association between apolipoprotein $E$ genotype and Alzheimer disease. A meta-analysis. APOE and Alzheimer Disease Meta Analysis Consortium. JAMA 278, 1349-1356, (1997). [PubMed: 9343467]

7. Corder EH et al. Protective effect of apolipoprotein E type 2 allele for late onset Alzheimer disease. Nat. Genet 7, 180-184, (1994). [PubMed: 7920638]

8. Neu SC et al. Apolipoprotein E Genotype and Sex Risk Factors for Alzheimer Disease A Metaanalysis. JAMA Neurol. 74, 1178-1189, (2017). [PubMed: 28846757]

9. Genin E et al. APOE and Alzheimer disease: a major gene with semi-dominant inheritance. Mol. Psychiatry 16, 903-907, (2011). [PubMed: 21556001]

10. Sando SB et al. APOE epsilon 4 lowers age at onset and is a high risk factor for Alzheimer's disease; a case control study from central Norway. BMC Neurol. 8, 9, (2008). [PubMed: 18416843]

11. Liu CC, Kanekiyo T, Xu H \& Bu G Apolipoprotein E and Alzheimer disease: risk, mechanisms and therapy. Nat. Rev. Neurol 9, 106-118, (2013). [PubMed: 23296339]

12. Shi $\mathrm{Y}$ et al. ApoE4 markedly exacerbates tau-mediated neurodegeneration in a mouse model of tauopathy. Nature 549, 523-527, (2017). [PubMed: 28959956]

13. Bras $\mathbf{J}$ et al. Genetic analysis implicates APOE, SNCA and suggests lysosomal dysfunction in the etiology of dementia with Lewy bodies. Hum. Mol. Genet 23, 6139-6146, (2014). [PubMed: 24973356]

14. Guerreiro R et al. Investigating the genetic architecture of dementia with Lewy bodies: a two-stage genome-wide association study. Lancet Neurol. 17, 64-74, (2018). [PubMed: 29263008] 
15. Tsuang D et al. APOE epsilon4 increases risk for dementia in pure synucleinopathies. JAMA Neurol. 70, 223-228, (2013). [PubMed: 23407718]

16. Huang X, Chen P, Kaufer DI, Troster AI \& Poole C Apolipoprotein E and dementia in Parkinson disease: a meta-analysis. Arch. Neurol 63, 189-193, (2006). [PubMed: 16476806]

17. Irwin DJ et al. Neuropathologic substrates of Parkinson disease dementia. Ann. Neurol 72, 587598, (2012). [PubMed: 23037886]

18. Tropea TF et al. APOE, thought disorder, and SPARE-AD predict cognitive decline in established Parkinson's disease. Mov. Disord 33, 289-297, (2018). [PubMed: 29168904]

19. Josephs KA et al. TDP-43 is a key player in the clinical features associated with Alzheimer's disease. Acta Neuropathol. 127, 811-824, (2014). [PubMed: 24659241]

20. Wennberg AM et al. Association of Apolipoprotein E epsilon4 With Transactive Response DNABinding Protein 43. JAMA Neurol. 75, 1347-1354, (2018). [PubMed: 30422173]

21. Yang H-S et al. Evaluation of TDP-43 proteinopathy and hippocampal sclerosis in relation to APOE $\varepsilon 4$ haplotype status: a community-based cohort study. Lancet Neurol. 17, 773-781, (2018). [PubMed: 30093249]

22. Mahley RW Apolipoprotein E: cholesterol transport protein with expanding role in cell biology. Science 240, 622-630, (1988). [PubMed: 3283935]

23. Xu Q et al. Profile and regulation of apolipoprotein E (ApoE) expression in the CNS in mice with targeting of green fluorescent protein gene to the ApoE locus. J. Neurosci 26, 4985-4994, (2006). [PubMed: 16687490]

24. Kang SS et al. Microglial translational profiling reveals a convergent APOE pathway from aging, amyloid, and tau. J Exp Med 215, 2235-2245, (2018). [PubMed: 30082275]

25. Wahrle SE et al. ABCA1 is required for normal central nervous system ApoE levels and for lipidation of astrocyte-secreted apoE. J. Biol. Chem 279, 40987-40993, (2004). [PubMed: 15269217]

26. Karten B, Campenot RB, Vance DE \& Vance JE Expression of ABCG1, but not ABCA1, correlates with cholesterol release by cerebellar astroglia. J. Biol. Chem 281, 4049-4057, (2006). [PubMed: 16352604]

27. LaDu MJ et al. Nascent astrocyte particles differ from lipoproteins in CSF. J. Neurochem 70, 2070-2081, (1998). [PubMed: 9572293]

28. Bu G Apolipoprotein E and its receptors in Alzheimer's disease: pathways, pathogenesis and therapy. Nat. Rev. Neurosci 10, 333-344, (2009). [PubMed: 19339974]

29. Kanekiyo T, Xu H \& Bu G ApoE and Abeta in Alzheimer's disease: accidental encounters or partners? Neuron 81, 740-754, (2014). [PubMed: 24559670]

30. Dong $\mathbf{J}$ et al. Interaction of the N-terminal domain of apolipoprotein E4 with heparin. Biochemistry 40, 2826-2834, (2001). [PubMed: 11258893]

31. Segelke BW et al. Conformational flexibility in the apolipoprotein E amino-terminal domain structure determined from three new crystal forms: implications for lipid binding. Protein Sci. 9, 886-897, (2000). [PubMed: 10850798]

32. Wilson C et al. Salt bridge relay triggers defective LDL receptor binding by a mutant apolipoprotein. Structure 2, 713-718, (1994). [PubMed: 7994571]

33. Dong LM et al. Human apolipoprotein E. Role of arginine 61 in mediating the lipoprotein preferences of the E3 and E4 isoforms. J. Biol. Chem 269, 22358-22365, (1994). [PubMed: 8071364]

34. Wilson C, Wardell MR, Weisgraber KH, Mahley RW \& Agard DA Three-dimensional structure of the LDL receptor-binding domain of human apolipoprotein E. Science 252, 1817-1822, (1991). [PubMed: 2063194]

35. Dong LM et al. Novel mechanism for defective receptor binding of apolipoprotein E2 in type III hyperlipoproteinemia. Nat. Struct. Biol 3, 718-722, (1996). [PubMed: 8756331]

36. Guttman M, Prieto JH, Handel TM, Domaille PJ \& Komives EA Structure of the minimal interface between ApoE and LRP. J. Mol. Biol 398, 306-319, (2010). [PubMed: 20303980]

37. Chen J, Li Q \& Wang J Topology of human apolipoprotein E3 uniquely regulates its diverse biological functions. Proc. Natl Acad. Sci. USA 108, 14813-14818, (2011). [PubMed: 21873229] 
38. Richter JE et al. Protein molecular modeling shows residue T599 is critical to wild-type function of POLG and description of a novel variant associated with the SANDO phenotype. Hum. Genome Var 5, 18016, (2018). [PubMed: 29644085]

39. Puschmann A et al. Heterozygous PINK1 p.G411S increases risk of Parkinson's disease via a dominant-negative mechanism. Brain 140, 98-117, (2017). [PubMed: 27807026]

40. Kayode O et al. An Acrobatic Substrate Metamorphosis Reveals a Requirement for Substrate Conformational Dynamics in Trypsin Proteolysis. J. Biol. Chem 291, 26304-26319, (2016). [PubMed: 27810896]

41. Caulfield TR, Fiesel FC \& Springer W Activation of the E3 ubiquitin ligase Parkin. Biochem. Soc. Trans 43, 269-274, (2015). [PubMed: 25849928]

42. Caulfield TR et al. Phosphorylation by PINK1 Releases the UBL Domain and Initializes the Conformational Opening of the E3 Ubiquitin Ligase Parkin. PLoS Comput. Biol 10, e1003935, (2014). [PubMed: 25375667]

43. Zhang YJ et al. The dual functions of the extreme N-terminus of TDP-43 in regulating its biological activity and inclusion formation. Hum. Mol. Genet 22, 3112-3122, (2013). [PubMed: 23575225]

44. Caulfield T \& Devkota B Motion of transfer RNA from the A/T state into the A-site using docking and simulations. Proteins 80, 2489-2500, (2012). [PubMed: 22730134]

45. Altschul SF et al. Gapped BLAST and PSI-BLAST: a new generation of protein database search programs. Nucleic Acids Res. 25, 3389-3402, (1997). [PubMed: 9254694]

46. Hooft RW, Sander C, Scharf M \& Vriend G The PDBFINDER database: a summary of PDB, DSSP and HSSP information with added value. Comput. Appl. Biosci 12, 525-529, (1996). [PubMed: 9021272]

47. Hooft RW, Vriend G, Sander C \& Abola EE Errors in protein structures. Nature 381, 272, (1996). [PubMed: 8692262]

48. Krieger E et al. Improving physical realism, stereochemistry, and side-chain accuracy in homology modeling: Four approaches that performed well in CASP8. Proteins 77 Suppl 9, 114-122, (2009). [PubMed: 19768677]

49. Frieden C, Wang H \& Ho CMW A mechanism for lipid binding to apoE and the role of intrinsically disordered regions coupled to domain-domain interactions. Proc. Natl Acad. Sci. USA 114, 6292-6297, (2017). [PubMed: 28559318]

50. Mondal T et al. ApoE: In Vitro Studies of a Small Molecule Effector. Biochemistry 55, 2613-2621, (2016). [PubMed: 27065061]

51. Frieden C ApoE: the role of conserved residues in defining function. Protein Sci. 24, 138-144, (2015). [PubMed: 25377861]

52. Garai K, Verghese PB, Baban B, Holtzman DM \& Frieden C The binding of apolipoprotein E to oligomers and fibrils of amyloid-beta alters the kinetics of amyloid aggregation. Biochemistry 53, 6323-6331, (2014). [PubMed: 25207746]

53. Frieden C \& Garai K Concerning the structure of apoE. Protein Sci. 22, 1820-1825, (2013). [PubMed: 24115173]

54. Ji ZS, Dichek HL, Miranda RD \& Mahley RW Heparan sulfate proteoglycans participate in hepatic lipaseand apolipoprotein E-mediated binding and uptake of plasma lipoproteins, including high density lipoproteins. J. Biol. Chem 272, 31285-31292, (1997). [PubMed: 9395455]

55. Hatters DM, Peters-Libeu CA \& Weisgraber KH Apolipoprotein E structure: insights into function. Trends Biochem. Sci 31, 445-454, (2006). [PubMed: 16820298]

56. Phillips MC Apolipoprotein E isoforms and lipoprotein metabolism. IUBMB Life 66, 616-623, (2014). [PubMed: 25328986]

57. Lane-Donovan C et al. Genetic Restoration of Plasma ApoE Improves Cognition and Partially Restores Synaptic Defects in ApoE-Deficient Mice. J. Neurosci 36, 10141-10150, (2016). [PubMed: 27683909]

58. Nielsen HM et al. Peripheral apoE isoform levels in cognitively normal APOE epsilon3/epsilon4 individuals are associated with regional gray matter volume and cerebral glucose metabolism. Alzheimers Res. Ther 9, 5, (2017). [PubMed: 28137305] 
59. Martinez-Morillo E et al. Total apolipoprotein E levels and specific isoform composition in cerebrospinal fluid and plasma from Alzheimer's disease patients and controls. Acta Neuropathol. 127, 633-643, (2014). [PubMed: 24633805]

60. Baker-Nigh AT et al. Human Central Nervous System (CNS) ApoE Isoforms Are Increased by Age, Differentially Altered by Amyloidosis, and Relative Amounts Reversed in the CNS Compared with Plasma. J. Biol. Chem 291, 27204-27218, (2016). [PubMed: 27793990]

61. Christensen DZ, Schneider-Axmann T, Lucassen PJ, Bayer TA \& Wirths O Accumulation of intraneuronal Abeta correlates with ApoE4 genotype. Acta Neuropathol. 119, 555-566, (2010). [PubMed: 20217101]

62. Kok E et al. Apolipoprotein E-dependent accumulation of Alzheimer disease-related lesions begins in middle age. Ann. Neurol 65, 650-657, (2009). [PubMed: 19557866]

63. Polvikoski T et al. Apolipoprotein E, dementia, and cortical deposition of beta-amyloid protein. N. Engl. J. Med 333, 1242-1247, (1995). [PubMed: 7566000]

64. Schmechel DE et al. Increased amyloid beta-peptide deposition in cerebral cortex as a consequence of apolipoprotein E genotype in late-onset Alzheimer disease. Proc. Natl Acad. Sci. USA 90, 9649-9653, (1993). [PubMed: 8415756]

65. Tiraboschi P et al. Impact of APOE genotype on neuropathologic and neurochemical markers of Alzheimer disease. Neurology 62, 1977-1983, (2004). [PubMed: 15184600]

66. Koffie RM et al. Apolipoprotein E4 effects in Alzheimer's disease are mediated by synaptotoxic oligomeric amyloid-beta. Brain 135, 2155-2168, (2012). [PubMed: 22637583]

67. Rannikmae K et al. APOE associations with severe CAA-associated vasculopathic changes: collaborative meta-analysis. J. Neurol. Neurosurg. Psychiatry 85, 300-305, (2014). [PubMed: 24163429]

68. Shinohara M et al. Impact of sex and APOE4 on cerebral amyloid angiopathy in Alzheimer's disease. Acta Neuropathol. 132, 225-234, (2016). [PubMed: 27179972]

69. Serrano-Pozo A, Qian J, Monsell SE, Betensky RA \& Hyman BT APOEepsilon2 is associated with milder clinical and pathological Alzheimer disease. Ann. Neurol 77, 917-929, (2015). [PubMed: 25623662]

70. Nelson PT et al. APOE-epsilon2 and APOE-epsilon4 correlate with increased amyloid accumulation in cerebral vasculature. J. Neuropathol. Exp. Neurol 72, 708-715, (2013). [PubMed: 23771217]

71. Nicoll JA et al. High frequency of apolipoprotein E epsilon 2 allele in hemorrhage due to cerebral amyloid angiopathy. Ann. Neurol 41, 716-721, (1997). [PubMed: 9189032]

72. Biffi A et al. Variants at APOE influence risk of deep and lobar intracerebral hemorrhage. Ann. Neurol 68, 934-943, (2010). [PubMed: 21061402]

73. Love $\mathrm{S}$ et al. Development, appraisal, validation and implementation of a consensus protocol for the assessment of cerebral amyloid angiopathy in post-mortem brain tissue. Am. J. Neurodegener. Dis 3, 19-32, (2014). [PubMed: 24754000]

74. Gonneaud J et al. Relative effect of APOE epsilon4 on neuroimaging biomarker changes across the lifespan. Neurology 87, 1696-1703, (2016). [PubMed: 27683850]

75. Kantarci $\mathrm{K}$ et al. APOE modifies the association between Abeta load and cognition in cognitively normal older adults. Neurology 78, 232-240, (2012). [PubMed: 22189452]

76. Sunderland T et al. Cerebrospinal fluid beta-amyloid1-42 and tau in control subjects at risk for Alzheimer's disease: the effect of APOE epsilon4 allele. Biol. Psychiatry 56, 670-676, (2004). [PubMed: 15522251]

77. Morris JC et al. APOE predicts amyloid-beta but not tau Alzheimer pathology in cognitively normal aging. Ann. Neurol 67, 122-131, (2010). [PubMed: 20186853]

78. Jack CR Jr. et al. Age, Sex, and APOE epsilon4 Effects on Memory, Brain Structure, and betaAmyloid Across the Adult Life Span. JAMA Neurol. 72, 511-519, (2015). [PubMed: 25775353]

79. Murphy KR et al. Mapping the effects of ApoE4, age and cognitive status on 18F-florbetapir PET measured regional cortical patterns of beta-amyloid density and growth. Neuroimage 78, 474-480, (2013). [PubMed: 23624169] 
80. Fleisher AS et al. Apolipoprotein E epsilon4 and age effects on florbetapir positron emission tomography in healthy aging and Alzheimer disease. Neurobiol. Aging 34, 1-12, (2013). [PubMed: 22633529]

81. Mishra S et al. Longitudinal brain imaging in preclinical Alzheimer disease: impact of APOE epsilon4 genotype. Brain 141, 1828-1839, (2018). [PubMed: 29672664]

82. Lim YY \& Mormino EC APOE genotype and early beta-amyloid accumulation in older adults without dementia. Neurology 89, 1028-1034, (2017). [PubMed: 28794245]

83. Grothe MJ, Villeneuve S, Dyrba M, Bartres-Faz D \& Wirth M Multimodal characterization of older APOE2 carriers reveals selective reduction of amyloid load. Neurology 88, 569-576, (2017). [PubMed: 28062720]

84. Chiang GC et al. Hippocampal atrophy rates and CSF biomarkers in elderly APOE2 normal subjects. Neurology 75, 1976-1981, (2010). [PubMed: 20980669]

85. Jansen WJ et al. Prevalence of cerebral amyloid pathology in persons without dementia: a metaanalysis. JAMA 313, 1924-1938, (2015). [PubMed: 25988462]

86. Berlau DJ, Corrada MM, Head E \& Kawas CH APOE epsilon2 is associated with intact cognition but increased Alzheimer pathology in the oldest old. Neurology 72, 829-834, (2009). [PubMed: 19255410]

87. Shinohara M et al. APOE2 Eases Cognitive Decline during Aging: Clinical and Preclinical Evaluations. Ann. Neurol 79, 758-774, (2016). [PubMed: 26933942]

88. Tarasoff-Conway JM et al. Clearance systems in the brain-implications for Alzheimer disease. Nat. Rev. Neurol 11, 457-470, (2015). [PubMed: 26195256]

89. Castellano JM et al. Human apoE isoforms differentially regulate brain amyloid-beta peptide clearance. Sci. Transl. Med 3, 89ra57, (2011).

90. Fitz NF et al. Abcal deficiency affects Alzheimer's disease-like phenotype in human ApoE4 but not in ApoE3-targeted replacement mice. J. Neurosci 32, 13125-13136, (2012). [PubMed: 22993429]

91. Deane R et al. apoE isoform-specific disruption of amyloid beta peptide clearance from mouse brain. J. Clin. Invest 118, 4002-4013, (2008). [PubMed: 19033669]

92. Robert $\mathbf{J}$ et al. Clearance of beta-amyloid is facilitated by apolipoprotein $\mathrm{E}$ and circulating highdensity lipoproteins in bioengineered human vessels. Elife 6, e29595, (2017). [PubMed: 28994390]

93. Ma Q et al. Blood-brain barrier-associated pericytes internalize and clear aggregated amyloidbeta42 by LRP1-dependent apolipoprotein E isoform-specific mechanism. Mol. Neurodegener 13, 57, (2018). [PubMed: 30340601]

94. Lin YT et al. APOE4 Causes Widespread Molecular and Cellular Alterations Associated with Alzheimer's Disease Phenotypes in Human iPSC-Derived Brain Cell Types. Neuron 98, 1294, (2018). [PubMed: 29953873]

95. Koistinaho $\mathrm{M}$ et al. Apolipoprotein $\mathrm{E}$ promotes astrocyte colocalization and degradation of deposited amyloid-beta peptides. Nat. Med 10, 719-726, (2004). [PubMed: 15195085]

96. Basak JM, Verghese PB, Yoon H, Kim J \& Holtzman DM Low-density lipoprotein receptor represents an apolipoprotein E-independent pathway of Abeta uptake and degradation by astrocytes. J. Biol. Chem 287, 13959-13971, (2012). [PubMed: 22383525]

97. Verghese PB et al. ApoE influences amyloid-beta (Abeta) clearance despite minimal apoE/Abeta association in physiological conditions. Proc. Natl Acad. Sci. USA 110, E1807-1816, (2013). [PubMed: 23620513]

98. Jiang Q et al. ApoE promotes the proteolytic degradation of Abeta. Neuron 58, 681-693, (2008). [PubMed: 18549781]

99. Lee CYD, Tse W, Smith JD \& Landreth GE Apolipoprotein E Promotes beta-Amyloid Trafficking and Degradation by Modulating Microglial Cholesterol Levels. J. Biol. Chem 287, 2032-2044, (2012). [PubMed: 22130662]

100. Saido T \& Leissring MA Proteolytic degradation of amyloid beta-protein. Cold Spring Harb. Perspect. Med 2, a006379, (2012). [PubMed: 22675659] 
101. Miners JS et al. Decreased expression and activity of neprilysin in Alzheimer disease are associated with cerebral amyloid angiopathy. J. Neuropathol. Exp. Neurol 65, 1012-1021, (2006). [PubMed: 17021406]

102. Cook DG et al. Reduced hippocampal insulin-degrading enzyme in late-onset Alzheimer's disease is associated with the apolipoprotein E-epsilon4 allele. Am. J. Pathol 162, 313-319, (2003). [PubMed: 12507914]

103. Weller RO, Subash M, Preston SD, Mazanti I \& Carare RO Perivascular drainage of amyloid-beta peptides from the brain and its failure in cerebral amyloid angiopathy and Alzheimer's disease. Brain Pathol. 18, 253-266, (2008). [PubMed: 18363936]

104. Hawkes CA et al. Disruption of arterial perivascular drainage of amyloid-beta from the brains of mice expressing the human APOE epsilon4 allele. PloS one 7, e41636, (2012). [PubMed: 22848551]

105. Louveau A et al. Understanding the functions and relationships of the glymphatic system and meningeal lymphatics. J. Clin. Invest 127, 3210-3219, (2017). [PubMed: 28862640]

106. Achariyar TM et al. Glymphatic distribution of CSF-derived apoE into brain is isoform specific and suppressed during sleep deprivation. Mol. Neurodegener 11, 74, (2016). [PubMed: 27931262]

107. Arosio P, Knowles TP \& Linse S On the lag phase in amyloid fibril formation. Phys. Chem. Chem. Phys 17, 7606-7618, (2015). [PubMed: 25719972]

108. Kim J, Basak JM \& Holtzman DM The role of apolipoprotein E in Alzheimer's disease. Neuron 63, 287-303, (2009). [PubMed: 19679070]

109. Liu CC et al. ApoE4 Accelerates Early Seeding of Amyloid Pathology. Neuron 96, 1024-1032 e1023, (2017). [PubMed: 29216449]

110. Huynh TPV et al. Age-Dependent Effects of apoE Reduction Using Antisense Oligonucleotides in a Model of beta-amyloidosis. Neuron 96, 1013-+, (2017). [PubMed: 29216448]

111. O'Brien RJ \& Wong PC Amyloid precursor protein processing and Alzheimer's disease. Annu. Rev. Neurosci 34, 185-204, (2011). [PubMed: 21456963]

112. Huang YA, Zhou B, Wernig M \& Sudhof TC ApoE2, ApoE3, and ApoE4 Differentially Stimulate APP Transcription and Abeta Secretion. Cell 168, 427-441 e421, (2017). [PubMed: 28111074]

113. Wang $\mathrm{C}$ et al. Gain of toxic apolipoprotein $\mathrm{E} 4$ effects in human iPSC-derived neurons is ameliorated by a small-molecule structure corrector. Nat. Med 24, 647-657, (2018). [PubMed: 29632371]

114. Nuriel T et al. The Endosomal-Lysosomal Pathway Is Dysregulated by APOE4 Expression in Vivo. Front. Neurosci 11, 702, (2017). [PubMed: 29311783]

115. Wang Y \& Mandelkow E Tau in physiology and pathology. Nat. Rev. Neurosci 17, 5-21, (2016). [PubMed: 26631930]

116. Leyns CEG \& Holtzman DM Glial contributions to neurodegeneration in tauopathies. Mol. Neurodegener 12, 50, (2017). [PubMed: 28662669]

117. Farfel JM, Yu L, De Jager PL, Schneider JA \& Bennett DA Association of APOE with tau-tangle pathology with and without beta-amyloid. Neurobiol. Aging 37, 19-25, (2016). [PubMed: 26481403]

118. Crary JF et al. Primary age-related tauopathy (PART): a common pathology associated with human aging. Acta Neuropathol. 128, 755-766, (2014). [PubMed: 25348064]

119. Tsuboi Y, Josephs KA, Cookson N \& Dickson DW APOE E4 is a determinant for Alzheimer type pathology in progressive supranuclear palsy. Neurology 60, 240-245, (2003). [PubMed: 12552038]

120. Tabaton $\mathrm{M}$ et al. Apolipoprotein E epsilon 4 allele frequency is not increased in progressive supranuclear palsy. Neurology 45, 1764-1765, (1995). [PubMed: 7675243]

121. Ikeda $\mathrm{K}$ et al. A subset of senile dementia with high incidence of the apolipoprotein $\mathrm{E}$ epsilon2 allele. Ann. Neurol 41, 693-695, (1997). [PubMed: 9153535]

122. Zhao $\mathrm{N}$ et al. APOE $\varepsilon 2$ is associated with increased tau pathology in primary tauopathy. Nat. Commun 9, 4388, (2018). [PubMed: 30348994] 
123. Ossenkoppele $\mathrm{R}$ et al. Tau PET patterns mirror clinical and neuroanatomical variability in Alzheimer's disease. Brain 139, 1551-1567, (2016). [PubMed: 26962052]

124. Brier MR et al. Tau and Abeta imaging, CSF measures, and cognition in Alzheimer's disease. Sci. Transl. Med 8, 338ra366, (2016).

125. Josephs KA et al. Beta-amyloid burden is not associated with rates of brain atrophy. Ann. Neurol 63, 204-212, (2008). [PubMed: 17894374]

126. Arriagada PV, Growdon JH, Hedley-Whyte ET \& Hyman BT Neurofibrillary tangles but not senile plaques parallel duration and severity of Alzheimer's disease. Neurology 42, 631-639, (1992). [PubMed: 1549228]

127. Brecht WJ et al. Neuron-specific apolipoprotein e4 proteolysis is associated with increased tau phosphorylation in brains of transgenic mice. J. Neurosci 24, 2527-2534, (2004). [PubMed: 15014128]

128. Federoff M, Jimenez-Rolando B, Nalls MA \& Singleton AB A large study reveals no association between APOE and Parkinson's disease. Neurobiol. Dis 46, 389-392, (2012). [PubMed: 22349451]

129. Spatola M \& Wider C Genetics of Parkinson's disease: the yield. Parkinsonism Relat. Disord 20 Suppl 1, S35-38, (2014). [PubMed: 24262184]

130. Spillantini MG et al. Alpha-synuclein in Lewy bodies. Nature 388, 839-840, (1997). [PubMed: 9278044]

131. Lashuel HA, Overk CR, Oueslati A \& Masliah E The many faces of alpha-synuclein: from structure and toxicity to therapeutic target. Nat. Rev. Neurosci 14, 38-48, (2013). [PubMed: 23254192]

132. Apaydin H, Ahlskog JE, Parisi JE, Boeve BF \& Dickson DW Parkinson disease neuropathology: later-developing dementia and loss of the levodopa response. Arch. Neurol 59, 102-112, (2002). [PubMed: 11790237]

133. McKeith IG et al. Diagnosis and management of dementia with Lewy bodies: Fourth consensus report of the DLB Consortium. Neurology 89, 88-100, (2017). [PubMed: 28592453]

134. Olichney JM et al. Cognitive decline is faster in Lewy body variant than in Alzheimer's disease. Neurology 51, 351-357, (1998). [PubMed: 9710002]

135. Selkoe DJ \& Hardy J The amyloid hypothesis of Alzheimer's disease at 25 years. EMBO Mol. Med 8, 595-608, (2016). [PubMed: 27025652]

136. Gallardo G, Schluter OM \& Sudhof TC A molecular pathway of neurodegeneration linking alphasynuclein to ApoE and Abeta peptides. Nat. Neurosci 11, 301-308, (2008). [PubMed: 18297066]

137. Dickson DW et al. APOE epsilon4 is associated with severity of Lewy body pathology independent of Alzheimer pathology. Neurology 91, e1182-e1195, (2018). [PubMed: 30143564]

138. Sugiyama $\mathrm{T}$ et al. A novel low-density lipoprotein receptor-related protein mediating cellular uptake of apolipoprotein E-enriched beta-VLDL in vitro. Biochemistry 39, 15817-15825, (2000). [PubMed: 11123907]

139. Brodeur J et al. LDLR-related protein 10 (LRP10) regulates amyloid precursor protein (APP) trafficking and processing: evidence for a role in Alzheimer's disease. Mol. Neurodegener 7, 31, (2012). [PubMed: 22734645]

140. Quadri M et al. LRP10 genetic variants in familial Parkinson's disease and dementia with Lewy bodies: a genome-wide linkage and sequencing study. Lancet Neurol. 17, 597-608, (2018). [PubMed: 29887161]

141. Neumann M et al. Ubiquitinated TDP-43 in frontotemporal lobar degeneration and amyotrophic lateral sclerosis. Science 314, 130-133, (2006). [PubMed: 17023659]

142. Itagaki S, McGeer PL, Akiyama H, Zhu S \& Selkoe D Relationship of microglia and astrocytes to amyloid deposits of Alzheimer disease. J. Neuroimmunol 24, 173-182, (1989). [PubMed: 2808689]

143. Song WM \& Colonna M The identity and function of microglia in neurodegeneration. Nat. Immunol 19, 1048-1058, (2018). [PubMed: 30250185]

144. Deczkowska A et al. Disease-Associated Microglia: A Universal Immune Sensor of Neurodegeneration. Cell 173, 1073-1081, (2018). [PubMed: 29775591] 
145. Rangaraju S et al. Identification and therapeutic modulation of a pro-inflammatory subset of disease-associated-microglia in Alzheimer's disease. Mol. Neurodegener 13, 24, (2018). [PubMed: 29784049]

146. Krasemann S et al. The TREM2-APOE Pathway Drives the Transcriptional Phenotype of Dysfunctional Microglia in Neurodegenerative Diseases. Immunity 47, 566-581 e569, (2017). [PubMed: 28930663]

147. Ulrich JD et al. ApoE facilitates the microglial response to amyloid plaque pathology. J. Exp. Med 215, 1047-1058, (2018). [PubMed: 29483128]

148. Keene CD, Cudaback E, Li X, Montine KS \& Montine TJ Apolipoprotein E isoforms and regulation of the innate immune response in brain of patients with Alzheimer's disease. Curr. Opin. Neurobiol 21, 920-928, (2011). [PubMed: 21907569]

149. Rodriguez GA, Tai LM, LaDu MJ \& Rebeck GW Human APOE4 increases microglia reactivity at Abeta plaques in a mouse model of Abeta deposition. J. Neuroinflamm 11, 111, (2014).

150. Shi Y \& Holtzman DM Interplay between innate immunity and Alzheimer disease: APOE and TREM2 in the spotlight. Nat. Rev. Immunol, (2018).

151. Yeh FL, Wang Y, Tom I, Gonzalez LC \& Sheng M TREM2 Binds to Apolipoproteins, Including APOE and CLU/APOJ, and Thereby Facilitates Uptake of Amyloid-Beta by Microglia. Neuron 91, 328-340, (2016). [PubMed: 27477018]

152. Atagi $Y$ et al. Apolipoprotein E Is a Ligand for Triggering Receptor Expressed on Myeloid Cells 2 (TREM2). J. Biol. Chem 290, 26043-26050, (2015). [PubMed: 26374899]

153. Bailey CC, DeVaux LB \& Farzan M The Triggering Receptor Expressed on Myeloid Cells 2 Binds Apolipoprotein E. J. Biol. Chem 290, 26033-26042, (2015). [PubMed: 26374897]

154. Jonsson $\mathrm{T}$ et al. Variant of TREM2 associated with the risk of Alzheimer's disease. N. Engl. J. Med 368, 107-116, (2013). [PubMed: 23150908]

155. Guerreiro R et al. TREM2 variants in Alzheimer's disease. N. Engl. J. Med 368, 117-127, (2013). [PubMed: 23150934]

156. Pimenova AA, Marcora E \& Goate AM A Tale of Two Genes: Microglial Apoe and Trem2. Immunity 47, 398-400, (2017). [PubMed: 28930654]

157. Jay TR, von Saucken VE \& Landreth GE TREM2 in Neurodegenerative Diseases. Mol. Neurodegener 12, 56, (2017). [PubMed: 28768545]

158. Efthymiou AG \& Goate AM Late onset Alzheimer's disease genetics implicates microglial pathways in disease risk. Mol. Neurodegener 12, 43, (2017). [PubMed: 28549481]

159. Parhizkar $\mathrm{S}$ et al. Loss of TREM2 function increases amyloid seeding but reduces plaqueassociated ApoE. Nat. Neurosci 22, 191-204, (2019). [PubMed: 30617257]

160. Arendt $\mathrm{T}$ et al. Plastic neuronal remodeling is impaired in patients with Alzheimer's disease carrying apolipoprotein epsilon 4 allele. J. Neurosci 17, 516-529, (1997). [PubMed: 8987775]

161. Ji Y et al. Apolipoprotein E isoform-specific regulation of dendritic spine morphology in apolipoprotein E transgenic mice and Alzheimer's disease patients. Neuroscience 122, 305-315, (2003). [PubMed: 14614898]

162. Sweet RA et al. Apolipoprotein E*4 (APOE*4) Genotype Is Associated with Altered Levels of Glutamate Signaling Proteins and Synaptic Coexpression Networks in the Prefrontal Cortex in Mild to Moderate Alzheimer Disease. Mol. Cell. Proteomics 15, 2252-2262, (2016). [PubMed: 27103636]

163. Love $\mathrm{S}$ et al. Premorbid effects of APOE on synaptic proteins in human temporal neocortex. Neurobiol. Aging 27, 797-803, (2006). [PubMed: 15979210]

164. Liraz O, Boehm-Cagan A \& Michaelson DM ApoE4 induces Abeta42, tau, and neuronal pathology in the hippocampus of young targeted replacement apoE4 mice. Mol. Neurodegener 8 , 16, (2013). [PubMed: 23684315]

165. Yong SM, Lim ML, Low CM \& Wong BS Reduced neuronal signaling in the ageing apolipoprotein-E4 targeted replacement female mice. Sci. Rep 4, 6580, (2014). [PubMed: 25301084]

166. Dumanis SB et al. ApoE4 decreases spine density and dendritic complexity in cortical neurons in vivo. J. Neurosci 29, 15317-15322, (2009). [PubMed: 19955384] 
167. Wang $\mathrm{C}$ et al. Human apoE4-targeted replacement mice display synaptic deficits in the absence of neuropathology. Neurobiol. Dis 18, 390-398, (2005). [PubMed: 15686968]

168. Klein RC, Mace BE, Moore SD \& Sullivan PM Progressive loss of synaptic integrity in human apolipoprotein E4 targeted replacement mice and attenuation by apolipoprotein E2. Neuroscience 171, 1265-1272, (2010). [PubMed: 20951774]

169. Chen Y, Durakoglugil MS, Xian X \& Herz J ApoE4 reduces glutamate receptor function and synaptic plasticity by selectively impairing ApoE receptor recycling. Proc. Natl Acad. Sci. USA 107, 12011-12016, (2010). [PubMed: 20547867]

170. Lane-Donovan C \& Herz J The ApoE receptors Vldlr and Apoer2 in central nervous system function and disease. J. Lipid Res 58, 1036-1043, (2017). [PubMed: 28292942]

171. Andrews-Zwilling Y et al. Apolipoprotein E4 causes age- and Tau-dependent impairment of GABAergic interneurons, leading to learning and memory deficits in mice. J. Neurosci 30, 13707-13717, (2010). [PubMed: 20943911]

172. Li G et al. GABAergic interneuron dysfunction impairs hippocampal neurogenesis in adult apolipoprotein E4 knockin mice. Cell Stem Cell 5, 634-645, (2009). [PubMed: 19951691]

173. Tensaouti Y, Stephanz EP, Yu TS \& Kernie SG ApoE Regulates the Development of Adult Newborn Hippocampal Neurons. eNeuro 5, ENEURO.0155-0118.2018, (2018).

174. Kara E et al. Isoform- and cell type-specific structure of apolipoprotein E lipoparticles as revealed by a novel Forster resonance energy transfer assay. J. Biol. Chem 292, 14720-14729, (2017). [PubMed: 28684412]

175. Fu Y et al. Apolipoprotein E lipoprotein particles inhibit amyloid-beta uptake through cell surface heparan sulphate proteoglycan. Mol. Neurodegener 11, 37, (2016). [PubMed: 27151330]

176. Zhao J et al. APOE epsilon4/epsilon4 diminishes neurotrophic function of human iPSC-derived astrocytes. Hum. Mol. Genet 26, 2690-2700, (2017). [PubMed: 28444230]

177. Heinsinger NM, Gachechiladze MA \& Rebeck GW Apolipoprotein E Genotype Affects Size of ApoE Complexes in Cerebrospinal Fluid. J. Neuropathol. Exp. Neurol 75, 918-924, (2016). [PubMed: 27516118]

178. Yassine HN et al. ABCA1-Mediated Cholesterol Efflux Capacity to Cerebrospinal Fluid Is Reduced in Patients With Mild Cognitive Impairment and Alzheimer's Disease. J. Am. Heart Assoc 5, e002886, (2016). [PubMed: 26873692]

179. Hanson AJ et al. Effect of apolipoprotein E genotype and diet on apolipoprotein E lipidation and amyloid peptides: randomized clinical trial. JAMA Neurol. 70, 972-980, (2013). [PubMed: 23779114]

180. Rebeck GW The role of APOE on lipid homeostasis and inflammation in normal brains. J. Lipid Res 58, 1493-1499, (2017). [PubMed: 28258087]

181. Fryer JD et al. The low density lipoprotein receptor regulates the level of central nervous system human and murine apolipoprotein E but does not modify amyloid plaque pathology in PDAPP mice. J. Biol. Chem 280, 25754-25759, (2005). [PubMed: 15888448]

182. Riddell DR et al. Impact of apolipoprotein E (ApoE) polymorphism on brain ApoE levels. J. Neurosci 28, 11445-11453, (2008). [PubMed: 18987181]

183. Ulrich JD et al. In vivo measurement of apolipoprotein $\mathrm{E}$ from the brain interstitial fluid using microdialysis. Mol. Neurodegener 8, 13, (2013). [PubMed: 23601557]

184. Petersen RC et al. Association of Elevated Amyloid Levels With Cognition and Biomarkers in Cognitively Normal People From the Community. JAMA Neurol. 73, 85-92, (2016). [PubMed: 26595683]

185. Jack CR Jr. \& Holtzman DM Biomarker modeling of Alzheimer's disease. Neuron 80, $1347-$ 1358, (2013). [PubMed: 24360540]

186. Bertens D, Knol DL, Scheltens P \& Visser PJ Temporal evolution of biomarkers and cognitive markers in the asymptomatic, MCI, and dementia stage of Alzheimer's disease. Alzheimers Dement. 11, 511-522, (2015). [PubMed: 25150730]

187. Willette AA et al. Association of Insulin Resistance With Cerebral Glucose Uptake in Late Middle-Aged Adults at Risk for Alzheimer Disease. JAMA Neurol. 72, 1013-1020, (2015). [PubMed: 26214150] 
188. Craft S Alzheimer disease: Insulin resistance and AD--extending the translational path. Nat. Rev. Immunol 8, 360-362, (2012).

189. Craft S, Cholerton B \& Baker LD Insulin and Alzheimer's disease: untangling the web. J. Alzheimers Dis 33 Suppl 1, S263-275, (2013). [PubMed: 22936011]

190. Hoyer S Glucose metabolism and insulin receptor signal transduction in Alzheimer disease. Eur. J. Pharmacol 490, 115-125, (2004). [PubMed: 15094078]

191. Steen E et al. Impaired insulin and insulin-like growth factor expression and signaling mechanisms in Alzheimer's disease--is this type 3 diabetes? J. Alzheimers Dis 7, 63-80, (2005). [PubMed: 15750215]

192. Ekblad LL et al. Midlife insulin resistance, APOE genotype, and late-life brain amyloid accumulation. Neurology 90, e1150-e1157, (2018). [PubMed: 29476033]

193. Jagust WJ \& Landau SM Apolipoprotein E, not fibrillar beta-amyloid, reduces cerebral glucose metabolism in normal aging. J. Neurosci 32, 18227-18233, (2012). [PubMed: 23238736]

194. Zhao N et al. Apolipoprotein E4 Impairs Neuronal Insulin Signaling by Trapping Insulin Receptor in the Endosomes. Neuron 96, 115-129 e115, (2017). [PubMed: 28957663]

195. Reiman EM et al. Preclinical evidence of Alzheimer's disease in persons homozygous for the epsilon 4 allele for apolipoprotein E. N. Engl. J. Med 334, 752-758, (1996). [PubMed: 8592548]

196. Peila R, Rodriguez BL \& Launer LJ Type 2 diabetes, APOE gene, and the risk for dementia and related pathologies: The Honolulu-Asia Aging Study. Diabetes 51, 1256-1262, (2002). [PubMed: 11916953]

197. Small GW et al. Apolipoprotein E type 4 allele and cerebral glucose metabolism in relatives at risk for familial Alzheimer disease. JAMA 273, 942-947, (1995). [PubMed: 7884953]

198. Reiman EM et al. Correlations between apolipoprotein E epsilon4 gene dose and brain-imaging measurements of regional hypometabolism. Proc. Natl Acad. Sci. USA 102, 8299-8302, (2005). [PubMed: 15932949]

199. Small GW et al. Cerebral metabolic and cognitive decline in persons at genetic risk for Alzheimer's disease. Proc. Natl Acad. Sci. USA 97, 6037-6042, (2000). [PubMed: 10811879]

200. Mosconi L et al. MCI conversion to dementia and the APOE genotype: a prediction study with FDG-PET. Neurology 63, 2332-2340, (2004). [PubMed: 15623696]

201. Drzezga A et al. Cerebral glucose metabolism in patients with AD and different APOE genotypes. Neurology 64, 102-107, (2005). [PubMed: 15642911]

202. Mosconi L et al. Brain metabolic decreases related to the dose of the ApoE e4 allele in Alzheimer's disease. J. Neurol. Neurosurg. Psychiatry 75, 370-376, (2004). [PubMed: 14966149]

203. Pardo JV \& Lee JT Atypical Localization and Dissociation between Glucose Uptake and Amyloid Deposition in Cognitively Normal APOE*E4 Homozygotic Elders Compared with Patients with Late-Onset Alzheimer's Disease. eNeuro 5, ENEURO.0396-0317.2018, (2018).

204. Reger MA et al. Effects of intranasal insulin on cognition in memory-impaired older adults: modulation by APOE genotype. Neurobiol. Aging 27, 451-458, (2006). [PubMed: 15964100]

205. Claxton A et al. Sex and ApoE genotype differences in treatment response to two doses of intranasal insulin in adults with mild cognitive impairment or Alzheimer's disease. J. Alzheimers Dis 35, 789-797, (2013). [PubMed: 23507773]

206. Claxton A et al. Long-acting intranasal insulin detemir improves cognition for adults with mild cognitive impairment or early-stage Alzheimer's disease dementia. J. Alzheimers Dis 44, 897906, (2015). [PubMed: 25374101]

207. Geijselaers SLC et al. Association of Cerebrospinal Fluid (CSF) Insulin with Cognitive Performance and CSF Biomarkers of Alzheimer's Disease. J. Alzheimers Dis 61, 309-320, (2018). [PubMed: 29154275]

208. Morris JK et al. Effect of APOE epsilon4 Genotype on Metabolic Biomarkers in Aging and Alzheimer's Disease. J. Alzheimers Dis 58, 1129-1135, (2017). [PubMed: 28550261]

209. Wu L, Zhang X \& Zhao L Human ApoE Isoforms Differentially Modulate Brain Glucose and Ketone Body Metabolism: Implications for Alzheimer's Disease Risk Reduction and Early Intervention. J. Neurosci 38, 6665-6681, (2018). [PubMed: 29967007] 
210. Johnson LA et al. Apolipoprotein E4 mediates insulin resistance-associated cerebrovascular dysfunction and the post-prandial response. J. Cereb. Blood Flow Metab, 271678X17746186, (2017).

211. Liu CC et al. Neuronal LRP1 regulates glucose metabolism and insulin signaling in the brain. J. Neurosci 35, 5851-5859, (2015). [PubMed: 25855193]

212. Sun JH et al. Genetics of Vascular Dementia: Systematic Review and Meta-Analysis. J. Alzheimers Dis 46, 611-629, (2015). [PubMed: 25835425]

213. Davidson Y et al. Apolipoprotein E epsilon4 allele frequency in vascular dementia. Dement. Geriatr. Cogn. Disord 22, 15-19, (2006). [PubMed: 16645276]

214. Sudre $\mathrm{CH}$ et al. APOE epsilon4 status is associated with white matter hyperintensities volume accumulation rate independent of AD diagnosis. Neurobiol. Aging 53, 67-75, (2017). [PubMed: 28235680]

215. Schilling S et al. APOE genotype and MRI markers of cerebrovascular disease: systematic review and meta-analysis. Neurology 81, 292-300, (2013). [PubMed: 23858411]

216. Halliday MR et al. Relationship Between Cyclophilin A Levels and Matrix Metalloproteinase 9 Activity in Cerebrospinal Fluid of Cognitively Normal Apolipoprotein E4 Carriers and BloodBrain Barrier Breakdown. JAMA Neurol. 70, 1198-1200, (2013). [PubMed: 24030206]

217. Halliday MR et al. Accelerated pericyte degeneration and blood-brain barrier breakdown in apolipoprotein E4 carriers with Alzheimer's disease. J. Cereb. Blood Flow Metab 36, 216-227, (2016). [PubMed: 25757756]

218. Alata W, Ye Y, St-Amour I, Vandal M \& Calon F Human apolipoprotein E varepsilon4 expression impairs cerebral vascularization and blood-brain barrier function in mice. J. Cereb. Blood Flow Metab 35, 86-94, (2015). [PubMed: 25335802]

219. Bell RD et al. Apolipoprotein E controls cerebrovascular integrity via cyclophilin A. Nature 485, 512-516, (2012). [PubMed: 22622580]

220. Koizumi $\mathrm{K}$ et al. Apoepsilon4 disrupts neurovascular regulation and undermines white matter integrity and cognitive function. Nat. Commun 9, 3816, (2018). [PubMed: 30232327]

221. Bien-Ly N et al. Lack of Widespread BBB Disruption in Alzheimer's Disease Models: Focus on Therapeutic Antibodies. Neuron 88, 289-297, (2015). [PubMed: 26494278]

222. Iturria-Medina $Y$ et al. Early role of vascular dysregulation on late-onset Alzheimer's disease based on multifactorial data-driven analysis. Nat. Commun 7, 11934, (2016). [PubMed: 27327500]

223. Janelidze $S$ et al. CSF biomarkers of neuroinflammation and cerebrovascular dysfunction in early Alzheimer disease. Neurology 91, e867-e877, (2018). [PubMed: 30054439]

224. Yamazaki Y et al. Selective loss of cortical endothelial tight junction proteins during Alzheimer's disease progression. Brain 142, 1077-1092, (2019). [PubMed: 30770921]

225. Nation DA et al. Blood-brain barrier breakdown is an early biomarker of human cognitive dysfunction. Nat. Med 25, 270-276, (2019). [PubMed: 30643288]

226. Ulrich V et al. Genetic variants of ApoE and ApoER2 differentially modulate endothelial function. Proc. Natl Acad. Sci. USA 111, 13493-13498, (2014). [PubMed: 25197062]

227. Tai LM et al. The role of APOE in cerebrovascular dysfunction. Acta Neuropathol. 131, 709-723, (2016). [PubMed: 26884068]

228. Groot $\mathrm{C}$ et al. Clinical phenotype, atrophy, and small vessel disease in APOE epsilon 2 carriers eth Alzheimer disease. Neurology 91, e1851-e1859, (2018). [PubMed: 30341156]

229. Hong C \& Tontonoz P Liver X receptors in lipid metabolism: opportunities for drug discovery. Nat. Rev. Drug Discov 13, 433-444, (2014). [PubMed: 24833295]

230. Burns MP et al. The effects of ABCA1 on cholesterol efflux and Abeta levels in vitro and in vivo. J. Neurochem 98, 792-800, (2006). [PubMed: 16771834]

231. Donkin JJ et al. ATP-binding Cassette Transporter A1 Mediates the Beneficial Effects of the Liver X Receptor Agonist GW3965 on Object Recognition Memory and Amyloid Burden in Amyloid Precursor Protein/Presenilin 1 Mice. J. Biol. Chem 285, 34144-34154, (2010). [PubMed: 20739291] 
232. Koldamova RP et al. The liver X receptor ligand T0901317 decreases amyloid beta production in vitro and in a mouse model of Alzheimer's disease. J. Biol. Chem 280, 4079-4088, (2005). [PubMed: 15557325]

233. Riddell DR et al. The LXR agonist TO901317 selectively lowers hippocampal Abeta42 and improves memory in the Tg2576 mouse model of Alzheimer's disease. Mol. Cell. Neurosci 34, 621-628, (2007). [PubMed: 17336088]

234. Vanmierlo $\mathrm{T}$ et al. Liver $\mathrm{X}$ receptor activation restores memory in aged AD mice without reducing amyloid. Neurobiol. Aging 32, 1262-1272, (2011). [PubMed: 19674815]

235. Cramer PE et al. ApoE-Directed Therapeutics Rapidly Clear beta-Amyloid and Reverse Deficits in AD Mouse Models. Science 335, 1503-1506, (2012). [PubMed: 22323736]

236. Fitz NF, Cronican AA, Lefterov I \& Koldamova R Comment on "ApoE-directed therapeutics rapidly clear beta-amyloid and reverse deficits in AD mouse models". Science 340, 924-c, (2013).

237. Boehm-Cagan A \& Michaelson DM Reversal of apoE4-Driven Brain Pathology and Behavioral Deficits by Bexarotene. J. Neurosci 34, 7293-7301, (2014). [PubMed: 24849361]

238. Tachibana $\mathrm{M}$ et al. Rescuing effects of RXR agonist bexarotene on aging-related synapse loss depend on neuronal LRP1. Exp. Neurol 277, 1-9, (2016). [PubMed: 26688581]

239. Veeraraghavalu $\mathrm{K}$ et al. Comment on "ApoE-directed therapeutics rapidly clear beta-amyloid and reverse deficits in AD mouse models". Science 340, 924-f, (2013).

240. Tesseur I et al. Comment on "ApoE-directed therapeutics rapidly clear beta-amyloid and reverse deficits in AD mouse models". Science 340, 924-e, (2013).

241. Price AR et al. Comment on "ApoE-directed therapeutics rapidly clear beta-amyloid and reverse deficits in AD mouse models". Science 340, 924-d, (2013).

242. Tai LM et al. Amyloid-beta pathology and APOE genotype modulate retinoid X receptor agonist activity in vivo. J. Biol. Chem 289, 30538-30555, (2014). [PubMed: 25217640]

243. Cummings JL et al. Double-blind, placebo-controlled, proof-of-concept trial of bexarotene Xin moderate Alzheimer's disease. Alzheimers Res. Ther 8, 4, (2016). [PubMed: 26822146]

244. Ghosal $\mathrm{K}$ et al. A randomized controlled study to evaluate the effect of bexarotene on amyloidbeta and apolipoprotein E metabolism in healthy subjects. Alzheimers Dement (N Y). 2, 110 120, (2016). [PubMed: 29067298]

245. Lalloyer $\mathrm{F}$ et al. Rexinoid bexarotene modulates triglyceride but not cholesterol metabolism via gene-specific permissivity of the RXR/LXR heterodimer in the liver. Arter. Thromb. Vasc. Biol 29, 1488-1495, (2009).

246. Finan GM et al. Bioactive Compound Screen for Pharmacological Enhancers of Apolipoprotein E in Primary Human Astrocytes. Cell Chem. Biol 23, 1526-1538, (2016). [PubMed: 27889409]

247. Dodart JC et al. Gene delivery of human apolipoprotein E alters brain Abeta burden in a mouse model of Alzheimer's disease. Proc. Natl Acad. Sci. USA 102, 1211-1216, (2005). [PubMed: 15657137]

248. Zhao L et al. Intracerebral adeno-associated virus gene delivery of apolipoprotein E2 markedly reduces brain amyloid pathology in Alzheimer's disease mouse models. Neurobiol. Aging 44, 159-172, (2016). [PubMed: 27318144]

249. Hudry E et al. Gene transfer of human Apoe isoforms results in differential modulation of amyloid deposition and neurotoxicity in mouse brain. Sci. Transl. Med 5, 212ra161, (2013).

250. Hu J et al. Opposing effects of viral mediated brain expression of apolipoprotein E2 (apoE2) and apoE4 on apoE lipidation and Abeta metabolism in apoE4-targeted replacement mice. Mol. Neurodegener 10, 6, (2015). [PubMed: 25871773]

251. Bien-Ly N, Gillespie AK, Walker D, Yoon SY \& Huang Y Reducing human apolipoprotein E levels attenuates age-dependent Abeta accumulation in mutant human amyloid precursor protein transgenic mice. J. Neurosci 32, 4803-4811, (2012). [PubMed: 22492035]

252. Kim J et al. Haploinsufficiency of human APOE reduces amyloid deposition in a mouse model of amyloid-beta amyloidosis. J. Neurosci 31, 18007-18012, (2011). [PubMed: 22159114]

253. Youmans KL et al. APOE4-specific changes in Abeta accumulation in a new transgenic mouse model of Alzheimer disease. J. Biol. Chem 287, 41774-41786, (2012). [PubMed: 23060451] 
254. Koldamova R, Staufenbiel M \& Lefterov I Lack of ABCA1 considerably decreases brain ApoE level and increases amyloid deposition in APP23 mice. J. Biol. Chem 280, 43224-43235, (2005). [PubMed: 16207713]

255. Wahrle SE et al. Deletion of Abca1 increases Abeta deposition in the PDAPP transgenic mouse model of Alzheimer disease. J. Biol. Chem 280, 43236-43242, (2005). [PubMed: 16207708]

256. Wahrle SE et al. Overexpression of ABCA1 reduces amyloid deposition in the PDAPP mouse model of Alzheimer disease. J. Clin. Invest 118, 671-682, (2008). [PubMed: 18202749]

257. Liao F et al. Anti-ApoE antibody given after plaque onset decreases Abeta accumulation and improves brain function in a mouse model of Abeta amyloidosis. J. Neurosci 34, 7281-7292, (2014). [PubMed: 24849360]

258. Kim J et al. Anti-apoE immunotherapy inhibits amyloid accumulation in a transgenic mouse model of Abeta amyloidosis. J. Exp. Med 209, 2149-2156, (2012). [PubMed: 23129750]

259. Liao $\mathrm{F}$ et al. Targeting of nonlipidated, aggregated apoE with antibodies inhibits amyloid accumulation. J. Clin. Invest 128, 2144-2155, (2018). [PubMed: 29600961]

260. Vitek MP et al. APOE-mimetic peptides reduce behavioral deficits, plaques and tangles in Alzheimer's disease transgenics. Neurodegener. Dis 10, 122-126, (2012). [PubMed: 22326991]

261. Handattu SP et al. In vivo and in vitro effects of an apolipoprotein e mimetic peptide on amyloidbeta pathology. J. Alzheimers Dis 36, 335-347, (2013). [PubMed: 23603398]

262. Ghosal $\mathrm{K}$ et al. The apolipoprotein-E-mimetic COG112 protects amyloid precursor protein intracellular domain-overexpressing animals from Alzheimer's disease-like pathological features. Neurodegener. Dis 12, 51-58, (2013). [PubMed: 22965147]

263. Mahley RW Central Nervous System Lipoproteins ApoE and Regulation of Cholesterol Metabolism. Arter. Thromb. Vasc. Biol 36, 1305-1315, (2016).

264. Mahley RW \& Huang Y Small-molecule structure correctors target abnormal protein structure and function: structure corrector rescue of apolipoprotein E4-associated neuropathology. J. Med. Chem 55, 8997-9008, (2012). [PubMed: 23013167]

265. Chen HK et al. Apolipoprotein E4 domain interaction mediates detrimental effects on mitochondria and is a potential therapeutic target for Alzheimer disease. J. Biol. Chem 286, 5215-5221, (2011). [PubMed: 21118811]

266. Chen HK et al. Small molecule structure correctors abolish detrimental effects of apolipoprotein E4 in cultured neurons. J. Biol. Chem 287, 5253-5266, (2012). [PubMed: 22158868]

267. Brodbeck J et al. Structure-dependent impairment of intracellular apolipoprotein E4 trafficking and its detrimental effects are rescued by small-molecule structure correctors. J. Biol. Chem 286, 17217-17226, (2011). [PubMed: 21454574]

268. Sadowski $\mathrm{M}$ et al. A synthetic peptide blocking the apolipoprotein E/beta-amyloid binding mitigates beta-amyloid toxicity and fibril formation in vitro and reduces beta-amyloid plaques in transgenic mice. Am. J. Pathol 165, 937-948, (2004). [PubMed: 15331417]

269. Sadowski MJ et al. Blocking the apolipoprotein E/amyloid-beta interaction as a potential therapeutic approach for Alzheimer's disease. Proc. Natl Acad. Sci. USA 103, 18787-18792, (2006). [PubMed: 17116874]

270. Liu S et al. Blocking the apolipoprotein E/amyloid beta interaction in triple transgenic mice ameliorates Alzheimer's disease related amyloid beta and tau pathology. J. Neurochem 128, 577591, (2014). [PubMed: 24117759]

271. Kuszczyk MA et al. Blocking the interaction between apolipoprotein E and Abeta reduces intraneuronal accumulation of Abeta and inhibits synaptic degeneration. Am. J. Pathol 182, 1750-1768, (2013). [PubMed: 23499462]

272. Pankiewicz JE et al. Blocking the apoE/Abeta interaction ameliorates Abeta-related pathology in APOE epsilon2 and epsilon4 targeted replacement Alzheimer model mice. Acta Neuropathol. Commun 2, 75, (2014). [PubMed: 24972680]

273. Zhao N, Liu CC, Qiao W \& Bu G Apolipoprotein E, Receptors, and Modulation of Alzheimer's Disease. Biol. Psychiatry 83, 347-357, (2018). [PubMed: 28434655]

274. Cao D, Fukuchi K, Wan H, Kim H \& Li L Lack of LDL receptor aggravates learning deficits and amyloid deposits in Alzheimer transgenic mice. Neurobiol. Aging 27, 1632-1643, (2006).

[PubMed: 16236385] 
275. Katsouri L \& Georgopoulos S Lack of LDL receptor enhances amyloid deposition and decreases glial response in an Alzheimer's disease mouse model. PloS one 6, e21880, (2011). [PubMed: 21755005]

276. Kim J et al. Overexpression of low-density lipoprotein receptor in the brain markedly inhibits amyloid deposition and increases extracellular A beta clearance. Neuron 64, 632-644, (2009). [PubMed: 20005821]

277. Kanekiyo T et al. Neuronal clearance of amyloid-beta by endocytic receptor LRP1. J. Neurosci 33, 19276-19283, (2013). [PubMed: 24305823]

278. Liu CC et al. Astrocytic LRP1 Mediates Brain Abeta Clearance and Impacts Amyloid Deposition. J. Neurosci 37, 4023-4031, (2017). [PubMed: 28275161]

279. Kanekiyo T, Liu CC, Shinohara M, Li J \& Bu G LRP1 in brain vascular smooth muscle cells mediates local clearance of Alzheimer's amyloid-beta. J. Neurosci 32, 16458-16465, (2012). [PubMed: 23152628]

280. Qosa H, Abuznait AH, Hill RA \& Kaddoumi A Enhanced Brain Amyloid-beta Clearance by Rifampicin and Caffeine as a Possible Protective Mechanism Against Alzheimer's Disease. J. Alzheimers Dis 31, 151-165, (2012). [PubMed: 22504320]

281. Shinohara M et al. Reduction of Brain beta-Amyloid (A beta) by Fluvastatin, a Hydroxymethylglutaryl-CoA Reductase Inhibitor, through Increase in Degradation of Amyloid Precursor Protein C-terminal Fragments (APP-CTFs) and A beta Clearance. J. Biol. Chem 285, 22091-22102, (2010). [PubMed: 20472556]

282. Mak AC et al. Effects of the absence of apolipoprotein e on lipoproteins, neurocognitive function, and retinal function. JAMA Neurol. 71, 1228-1236, (2014). [PubMed: 25111166]

283. Centeno EGZ, Cimarosti H \& Bithell A 2D versus 3D human induced pluripotent stem cellderived cultures for neurodegenerative disease modelling. Mol. Neurodegener 13, 27, (2018). [PubMed: 29788997]

284. Karch CM \& Goate AM Alzheimer's disease risk genes and mechanisms of disease pathogenesis. Biol. Psychiatry 77, 43-51, (2015). [PubMed: 24951455]

285. Carmona S, Hardy J \& Guerreiro R The genetic landscape of Alzheimer disease. Handb Clin Neurol 148, 395-408, (2018). [PubMed: 29478590]

286. Alzgene. Meta-analysis of all published AD association studies (case-control only) APOE_E2/3/4. http://www.alzgene.org/meta.asp?geneID=83, (2010).

287. Mattsson $\mathrm{N}$ et al. Prevalence of the apolipoprotein E epsilon4 allele in amyloid beta positive subjects across the spectrum of Alzheimer's disease. Alzheimers Dement. 14, 913-924, (2018). [PubMed: 29601787]

288. Cacace R, Sleegers K \& Van Broeckhoven C Molecular genetics of early-onset Alzheimer's disease revisited. Alzheimers Dement. 12, 733-748, (2016). [PubMed: 27016693]

289. van Duijn CM et al. Apolipoprotein E4 allele in a population-based study of early-onset Alzheimer's disease. Nat. Genet 7, 74-78, (1994). [PubMed: 8075646]

290. Chartier-Harlin MC et al. Apolipoprotein E, epsilon 4 allele as a major risk factor for sporadic early and late-onset forms of Alzheimer's disease: analysis of the 19q13.2 chromosomal region. Hum. Mol. Genet 3, 569-574, (1994). [PubMed: 8069300]

291. Houlden $\mathrm{H}$ et al. ApoE genotype is a risk factor in nonpresenilin early-onset Alzheimer's disease families. Am. J. Med. Genet 81, 117-121, (1998). [PubMed: 9514597]

292. Sorbi S et al. Epistatic effect of APP717 mutation and apolipoprotein E genotype in familial Alzheimer's disease. Ann. Neurol 38, 124-127, (1995). [PubMed: 7611715]

293. Pastor P et al. Apolipoprotein Eepsilon4 modifies Alzheimer's disease onset in an E280A PS1 kindred. Ann. Neurol 54, 163-169, (2003). [PubMed: 12891668]

294. Wijsman EM et al. APOE and other loci affect age-at-onset in Alzheimer's disease families with PS2 mutation. Am. J. Med. Genet. B Neuropsychiatr. Genet 132B, 14-20, (2005). [PubMed: 15389756]

295. Velez JI et al. APOE*E2 allele delays age of onset in PSEN1 E280A Alzheimer's disease. Mol. Psychiatry 21, 916-924, (2016). [PubMed: 26619808]

296. Ryman DC et al. Symptom onset in autosomal dominant Alzheimer disease: a systematic review and meta-analysis. Neurology 83, 253-260, (2014). [PubMed: 24928124] 
297. Altmann A, Tian L, Henderson VW \& Greicius MD Sex modifies the APOE-related risk of developing Alzheimer disease. Ann. Neurol 75, 563-573, (2014). [PubMed: 24623176]

298. Buckley RF et al. Sex, amyloid, and APOE epsilon4 and risk of cognitive decline in preclinical Alzheimer's disease: Findings from three well-characterized cohorts. Alzheimers Dement. 14, 1193-1203, (2018). [PubMed: 29803541]

299. Deming Y et al. Sex-specific genetic predictors of Alzheimer's disease biomarkers. Acta Neuropathol. 136, 857-872, (2018). [PubMed: 29967939]

300. Hohman TJ et al. Sex-Specific Association of Apolipoprotein E With Cerebrospinal Fluid Levels of Tau. JAMA Neurol. 75, 989-998, (2018). [PubMed: 29801024]

301. Buckley RF et al. Sex Differences in the Association of Global Amyloid and Regional Tau Deposition Measured By Positron Emission Tomography in Clinically Normal Older Adults. JAMA Neurol. 76, 542-551, (2019). [PubMed: 30715078]

302. Sundermann EE, Tran M, Maki PM \& Bondi MW Sex differences in the association between apolipoprotein E epsilon4 allele and Alzheimer's disease markers. Alzheimers Dement. 10, 438447, (2018).

303. Caselli RJ et al. Longitudinal modeling of age-related memory decline and the APOE epsilon4 effect. N. Engl. J. Med 361, 255-263, (2009). [PubMed: 19605830]

304. Caselli RJ et al. Longitudinal changes in cognition and behavior in asymptomatic carriers of the APOE e4 allele. Neurology 62, 1990-1995, (2004). [PubMed: 15184602]

305. Caselli RJ et al. Longitudinal modeling of frontal cognition in APOE epsilon4 homozygotes, heterozygotes, and noncarriers. Neurology 76, 1383-1388, (2011). [PubMed: 21502596]

306. Bonham LW et al. Age-dependent effects of APOE epsilon4 in preclinical Alzheimer's disease. Ann. Clin. Transl. Neurol 3, 668-677, (2016). [PubMed: 27648456]

307. Ferrari $\mathrm{C}$ et al. How can elderly apolipoprotein E epsilon 4 carriers remain free from dementia? Neurobiol. Aging 34, 13-21, (2013). [PubMed: 22503000]

308. Head D et al. Exercise Engagement as a Moderator of the Effects of APOE Genotype on Amyloid Deposition. Arch. Neurol 69, 636-643, (2012). [PubMed: 22232206]

309. Stocker H, Mollers T, Perna L \& Brenner H The genetic risk of Alzheimer's disease beyond APOE epsilon4: systematic review of Alzheimer's genetic risk scores. Transl. Psychiatry 8, 166, (2018). [PubMed: 30143603]

310. Escott-Price V, Myers AJ, Huentelman M \& Hardy J Polygenic risk score analysis of pathologically confirmed Alzheimer disease. Ann. Neurol 82, 311-314, (2017). [PubMed: 28727176]

311. Montine TJ \& Montine KS Precision medicine: Clarity for the clinical and biological complexity of Alzheimer's and Parkinson's diseases. J. Exp. Med 212, 601-605, (2015). [PubMed: 25941321]

312. Salloway $\mathrm{S}$ et al. Two phase 3 trials of bapineuzumab in mild-to-moderate Alzheimer's disease. N. Engl. J. Med 370, 322-333, (2014). [PubMed: 24450891]

313. Craft $\mathrm{S}$ et al. Insulin effects on glucose metabolism, memory, and plasma amyloid precursor protein in Alzheimer's disease differ according to apolipoprotein-E genotype. Ann. N Y Acad. Sci 903, 222-228, (2000). [PubMed: 10818510]

314. Reger MA et al. Intranasal insulin administration dose-dependently modulates verbal memory and plasma amyloid-beta in memory-impaired older adults. J. Alzheimers Dis 13, 323-331, (2008). [PubMed: 18430999]

315. Petersen RC et al. Vitamin $\mathrm{E}$ and donepezil for the treatment of mild cognitive impairment. N. Engl. J. Med 352, 2379-2388, (2005). [PubMed: 15829527] 


\section{Key points}

- $\quad$ The apolipoprotein $\mathrm{E}(A P O E)$ gene has three major allelic variants, $\varepsilon 2, \varepsilon 3$ and $\varepsilon 4 ; A P O E^{*} \varepsilon 4$ is associated with an increased risk and lower age of onset of Alzheimer disease (AD), whereas $A P O E^{*} \mathcal{E} 2$ seems to confer protection against $\mathrm{AD}$.

- Increasing evidence suggests that the effect of $A P O E^{*} \varepsilon 4$ on $\mathrm{AD}$ risk is exerted through inhibition of amyloid- $\beta$ (A $\beta)$ clearance and promotion of $A \beta$ aggregation.

- APOE influences tau pathology and tau-mediated neurodegeneration in an isoform-dependent manner, although the relevance of this observation to $\mathrm{AD}$ pathogenesis requires further investigation.

- $\quad$ APOE4 also contributes to AD pathogenesis by impairing microglial responsiveness, lipid transport, synaptic integrity and plasticity, glucose metabolism, and cerebrovascular integrity and function; some of these effects are independent of $A \beta$-related pathways.

- $\quad$ Current research into APOE-targeted AD therapeutic strategies aims to modulate APOE quantity and lipidation, APOE structural properties, APOE$\mathrm{A} \beta$ interaction, and APOE receptor expression. 


\section{Box 1:}

\section{APOE polymorphism as a risk determinant for AD}

Numerous susceptibility genes (or loci) and coding variants associated with the risk of developing Alzheimer disease (AD) have been identified ${ }^{284,285}$. However, owing to its large effect size and high prevalence, the apolipoprotein $\mathrm{E}$ ( $A P O E)$ polymorphism is considered to be the strongest genetic risk determinant for late-onset AD (Table 1). According to a meta-analysis, which included African American, white, Hispanic and Japanese individuals, the odds ratio (OR) for AD development in individuals with one allele of APOE2 is 0.621 (95\% CI 0.456-0.85) compared with individuals homozygous for $A P O E^{*} \varepsilon 3$. By contrast, the $\mathrm{OR}$ for $\mathrm{AD}$ development in individuals carrying one $A P O E^{*} \varepsilon 4$ allele is 3.68 (95\% CI 3.30-4.11) compared with individuals homozygous for $A P O E^{*} \varepsilon 3^{286}$. Importantly, $A P O E^{*} \varepsilon 4$ both increases the risk of $\mathrm{AD}^{6,8,9}$ and lowers the age of disease onset ${ }^{4,10}$ in an allele number-dependent manner. A study that included $>17,000$ white individuals showed that the ORs for AD development were 2.64 and 3.63, respectively, in individuals with the $A P O E^{*} \varepsilon 2 / \varepsilon 4$ and $A P O E^{*} \varepsilon 3 / \varepsilon 4$ genotypes, in relation to those with the $A P O E^{*} \varepsilon 3 / \varepsilon 3$ genotype ${ }^{9}$. The OR increased dramatically to 14.49 for individuals with the $A P O E^{*} \varepsilon 4 / \mathcal{E} 4$ genotype (Table 2$)^{9}$. In addition, compared with $A P O E^{*} \varepsilon 4$ non-carriers, carrying one $A P O E^{*} \varepsilon 4$ allele brings the onset of $\mathrm{AD}$ forward by $2-5$ years ${ }^{4,10}$, and carrying two $A P O E^{*} \varepsilon 4$ alleles brings onset forward by 510 years. The average allele frequency of $A P O E^{*} \varepsilon 4$ in cognitively healthy individuals across African American, white, Hispanic and Japanese populations is 9-20\% 286 ; however, it is dramatically increased to $\sim 40 \%$ among patients with AD (Table 1$)^{6,10}$, further highlighting the strong association of $A P O E^{*} \varepsilon 4$ with the risk of AD. A study published in 2018 showed that the prevalence of $A P O E^{*} \varepsilon 4$ was $66 \%$ in individuals with biomarker-confirmed AD-type dementia ${ }^{287}$.

Ethnicity might influence the magnitude of the $A P O E^{*} \varepsilon 4$-associated risk of developing AD. For example, when compared with white individuals ${ }^{6}$, the association of $A P O E^{*} \varepsilon 4$ with $\mathrm{AD}$ risk is weaker among African American and Hispanic individuals, but is stronger in Japanese individuals. Understanding the mechanism by which traits such as ethnicity and sex (Box 3 ) influence the association of $A P O E^{*} \varepsilon 4$ with AD risk might lead to the identification of modifiable factors that promote cognitive resilience in certain $A P O E^{*} \varepsilon 4$ carriers. 


\section{Box 2:}

\section{APOE polymorphism and early-onset AD}

The apolipoprotein $\mathrm{E} \varepsilon 4$ allele ( $\left.A P O E^{*} \varepsilon 4\right)$ is associated with an increased risk of earlyonset Alzheimer disease (EOAD) $)^{9,288}$, the symptoms of which develop at $\$ 55$ years of age. The presence of two $A P O E^{*} \varepsilon 4$ alleles is sufficient to increase the risk of EOAD regardless of family history of dementia ${ }^{289}$. By contrast, carrying one allele of $A P O E^{*} \varepsilon 4$ increases the risk of EOAD only in individuals with a positive family history of the disease ${ }^{289}$. The allele frequency of $A P O E^{*} \varepsilon 4$ is higher in individuals with EOAD than in healthy controls ${ }^{290,291}$, further supporting an association of $A P O E^{*} \varepsilon 4$ with the risk of EOAD. Furthermore, $A P O E^{*} \varepsilon 4$ decreases the age of onset of EOAD in families carrying amyloid precursor protein $(A P P)^{292}$, presenilin $1(P S E N I)^{293}$ or PSEN $2^{294}$ mutations, whereas $A P O E^{*} \varepsilon 2$ delays age of onset in those carrying PSEN1 mutations ${ }^{295}$. Overall, the impact of $A P O E$ polymorphism on the risk and age of onset of EOAD seems to be similar to that of $A P O E$ polymorphism on late-onset $\mathrm{AD}$, at least with respect to the directionality of effect. However, the available evidence is insufficient to draw conclusions about the relative dose effects of $A P O E^{*} \varepsilon 4$ and $A P O E^{*} \varepsilon 2$ alleles in individuals with EOAD who have different genetic backgrounds. Of note, in individuals with autosomal dominant $\mathrm{AD}$, family history and mutation type explain substantial portions of the observed variance in the age of symptom onset ${ }^{296}$, suggesting that the impact of $A P O E$ polymorphism on age of onset differs among subtypes of individuals with EOAD. 


\section{Box 3:}

\section{Sex-specific association of $A P O E^{\star} \varepsilon 4$ with $A D$}

The apolipoprotein $\mathrm{E} \varepsilon 4$ allele ( $A P O E^{*} \varepsilon 4$ ) seems to interact with sex to modify the risk of Alzheimer disease (AD). Women carrying one or two copies of $A P O E^{*} \varepsilon 4$ have a greater risk of developing $\mathrm{AD}$ than men with the same $A P O E$ genotype $^{6}$. In addition, cognitively healthy women carrying $A P O E^{*} \varepsilon 4$ are more likely to progress to mild cognitive impairment and Alzheimer disease (AD) than are men carrying $A P O E^{*} \varepsilon 4^{297}$. One study showed that among $A P O E^{*} \varepsilon 4$ carriers aged $65-75$ years, women had a greater risk of $\mathrm{AD}$ than did men ${ }^{8}$. A post hoc analysis of imaging data sets from cognitively healthy individuals who carried $A P O E^{*} \varepsilon 4$ and were positive for amyloid- $\beta(\mathrm{A} \beta)$ deposition on an amyloid-PET scan suggested that age-related cognitive decline was faster in the women than in the men ${ }^{298}$. A stronger association between $A P O E^{*} \varepsilon 4$ and elevated cerebrospinal fluid tau levels ${ }^{297,299,300}$ was observed in women than in men, particularly among A $\beta$-positive individuals ${ }^{299,300}$. Thus, the increased risk of $A D$ in women carrying $A P O E^{*} \varepsilon 4$ might be attributed to increased susceptibility to $\mathrm{A} \beta$ pathology, leading to accelerated neuronal damage. By contrast, no sex difference was observed in the association of $A P O E^{*} \varepsilon 4$ with regional tau deposition in clinically healthy individuals ${ }^{301}$. Comprehensive studies investigating sex differences in the association of $A P O E^{*} \varepsilon 4$ with $\mathrm{AD}-$ related biomarkers at different stages of $\mathrm{AD}$ development ${ }^{302}$ would help us to better understand the mechanisms by which $A P O E^{*} \mathcal{E} 4$ confers an increased risk of $\mathrm{AD}$ in women. 


\section{Box 4:}

\section{APOE genotype as a guide for precision medicine}

The aim of precision medicine is to tailor therapeutic interventions to an individual's predisposition to disease, disease progression and response to therapy. A strategy in which medical interventions for Alzheimer disease (AD) are guided by apolipoprotein $\mathrm{E}$ $(A P O E)$ polymorphisms, within the framework of precision medicine, might hold promise. In cognitively healthy individuals, the presence of $A P O E^{*} \varepsilon 4$ correlates with earlier and greater memory decline $e^{303-305}$ and progression to mild cognitive impairment or $\mathrm{AD}^{306}$. On the other hand, advanced education, active leisure activities and good vascular health are all likely to reduce the risk of $A P O E^{*} \varepsilon 4$-mediated cognitive decline ${ }^{307}$. A sedentary lifestyle is associated with higher amyloid- $\beta(\mathrm{A} \beta)$ deposition in cognitively healthy individuals carrying $A P O E^{*} \varepsilon 4^{308}$. Thus, at least in the cognitively healthy population, $A P O E$ genotyping, when performed as part of the polygenic risk score analysis ${ }^{309,310}$ and/or combined with pathological biomarker status, might be helpful in assessing the potential risk of $\mathrm{AD}$ and age-related cognitive decline. The early detection of latent pathological processes is an integral part of precision medicine ${ }^{311}$ as it provides greater opportunities for effective intervention, including lifestyle changes. If the initiation of $\mathrm{A} \beta$ pathology is detected, different types of interventions could be considered depending on the individual's $A P O E$ genotype (FIG. 5).

In several clinical studies, $A P O E^{*} \varepsilon 4$ carriers and non-carriers responded differently to treatment for $\mathrm{AD}$. In phase III trials of bapineuzumab, a humanized anti-A $\beta$ monoclonal antibody, in individuals with mild-to-moderate $\mathrm{AD}, A P O E^{*} \varepsilon 4$ status was associated with differences in key biomarker outcomes including $\mathrm{A} \beta$ metabolism and tau pathology 312 . In $A P O E^{*} 44$ carriers $\mathrm{A} \beta$ deposition detected by PET imaging remained unchanged in individuals treated with bapineuzumab $\left(0.5 \mathrm{mg} \mathrm{kg}^{-1}\right)$, whereas individuals receiving placebo showed increases in $\mathrm{A} \beta$ deposition over the course of 71 weeks. By contrast, in individuals not carrying $A P O E^{*} \varepsilon 4$, no increase in $\mathrm{A} \beta$ deposition was observed in the placebo groups, and there was no difference between the placebo group and individuals receiving $0.5 \mathrm{mg} / \mathrm{kg}$ or $1.0 \mathrm{mg} / \mathrm{kg}$ bapinezumab. In addition, $A P O E$ genotype seems to influence the outcomes of treatment with intranasal insulin ${ }^{204-206,313,314}$ and cholinesterase inhibitors $^{315}$ in individuals with $\mathrm{AD}$. For example, $A P O E^{*} \varepsilon 4$ non-carriers, but not $A P O E^{*} \varepsilon 4$ carriers, show memory facilitation after intravenous insulin administration $^{313}$. Acute administration of short-acting intranasal insulin improves verbal memory in $A P O E^{*} \varepsilon 4$ non-carriers but not in $A P O E^{*} \varepsilon 4$ carriers ${ }^{314}$. Interestingly, longacting intranasal insulin treatment in patients with $\mathrm{AD}$ leads to memory improvement in $A P O E^{*} \varepsilon 4$ carriers but worsening in $A P O E^{*} \varepsilon 4$ non-carriers ${ }^{206}$. Further understanding the relationship between $A P O E$ genotype and treatment response will improve delivery of individualized $\mathrm{AD}$ treatment. As such, the $A P O E$ genotype could serve as a guide for precision medicine. Given its strong AD risk-determining effect, however, there are ethical considerations pertaining to human genomic-based medicine that need to be taken into consideration when testing the $A P O E$ genotype. 


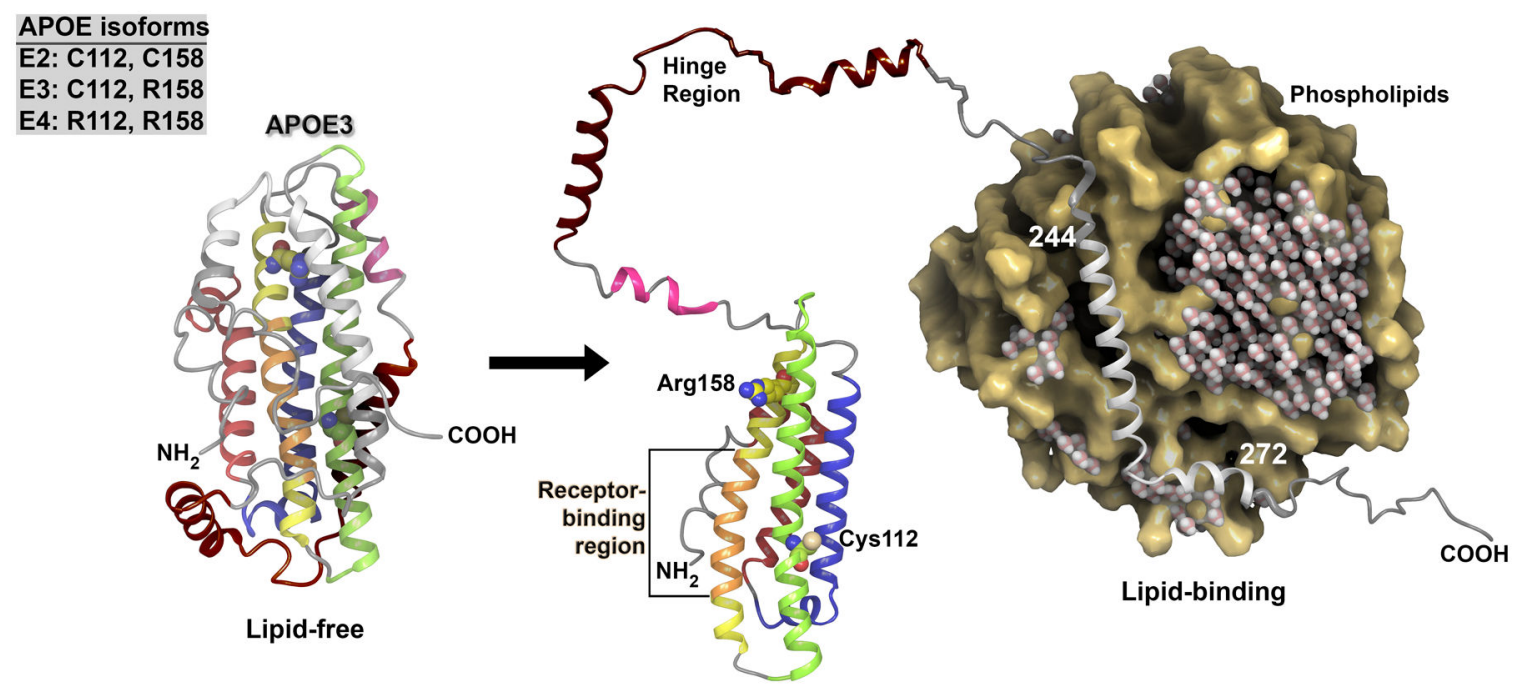

Figure 1: Structure of lipid-free and lipid-bound APOE3.

The structure of apolipoprotein E3 (APOE3) in the lipid-free state is shown on the left. APOE consists of multiple helices: a 4-helix bundle that consists of helix 2 (red), helix 3 (blue), helix 4 (green) and helix 5 (yellow and orange), hinge helices (pink and brown), and carboxyl-terminal domains that include lipid-binding residues and helices (translucent grey). The receptor-binding region (orange) is located on helix 5. The APOE isoforms differ at two residues only, and the residue composition for each isoform is given in the inset box. Isoform-specific residues (Arg158 and Cys112) are indicated on the structure of APOE3, with labels and carbons, shown as a van der Waals representation and coloured to match the helix with the residue. The lipid-bound structure of APOE3 is shown on the right. In its lipid-bound state, APOE3 demonstrates release of both the hinge region and the lipidbinding region, which causes the receptor binding region to be exposed. The crucial lipidbinding region includes residues 244-272. The lipid particle is shown in cross-section to allow better visualization of the APOE binding region. Water molecules depicted within the lipid particle illustrate the aqueous conditions and demonstrate the exclusion of water on binding of APOE3. The positively charged residues within the receptor-binding region in helix 5 (residues 136-150) interact with the negatively charged residues in the ligandbinding domains of LDL receptor family members; however, the precise binding structure of APOE with its receptors remains to be determined. 

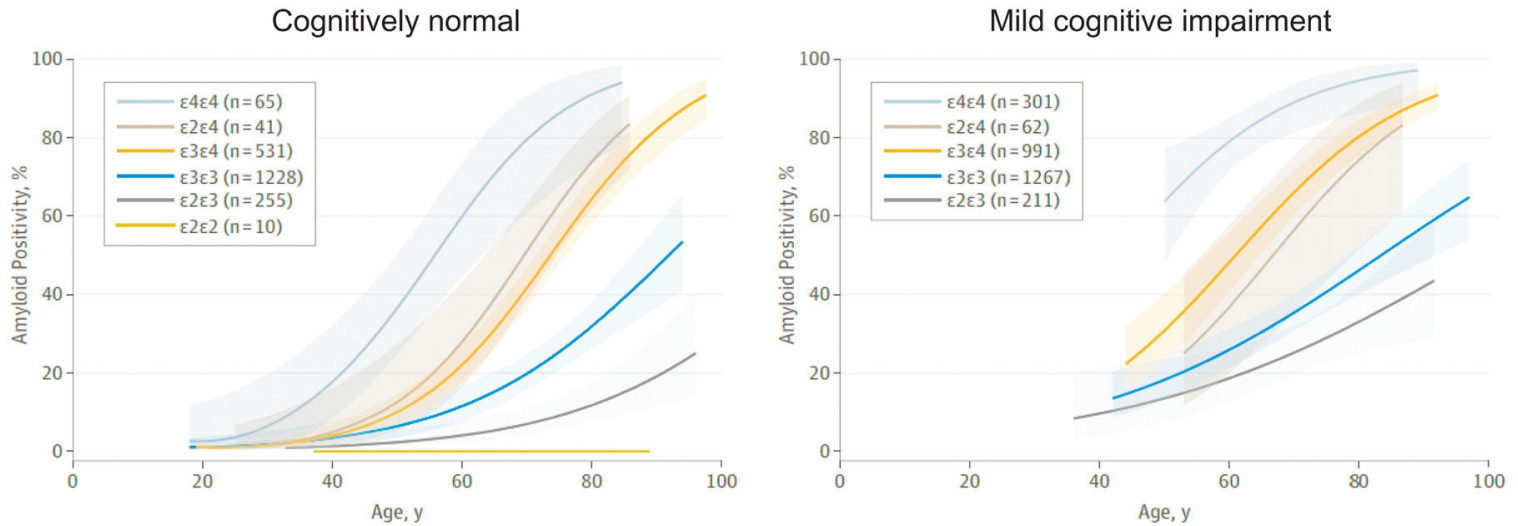

Figure 2: APOE genotype and amyloid positivity.

Estimated probabilities of amyloid positivity according to apolipoprotein $\mathrm{E}$ ( $A P O E$ )

genotype, plotted against age in cognitively healthy individuals and individuals with mild cognitive impairment (MCI). Shaded areas represent $95 \%$ CIs. In both groups, $A P O E^{*} \varepsilon 4 / \varepsilon 4$ individuals are more likely to be positive for amyloid pathology than individuals with any other genotype, whereas $A P O E^{*} \varepsilon 2 / \varepsilon 2$ individuals have the lowest probability of amyloid positivity. Also note that $A P O E^{*} \varepsilon 4$ is a strong driver of $\mathrm{A} \beta$ positivity irrespective of the presence of $A P O E^{*} \varepsilon 2$ or $A P O E^{*} \varepsilon 3$. Data for $A P O E^{*} \varepsilon 2 / \varepsilon 2$ individuals are not shown in the right panel owing to a small sample size. Adapted with permission from REF. ${ }^{85}$, American Medical Association. 


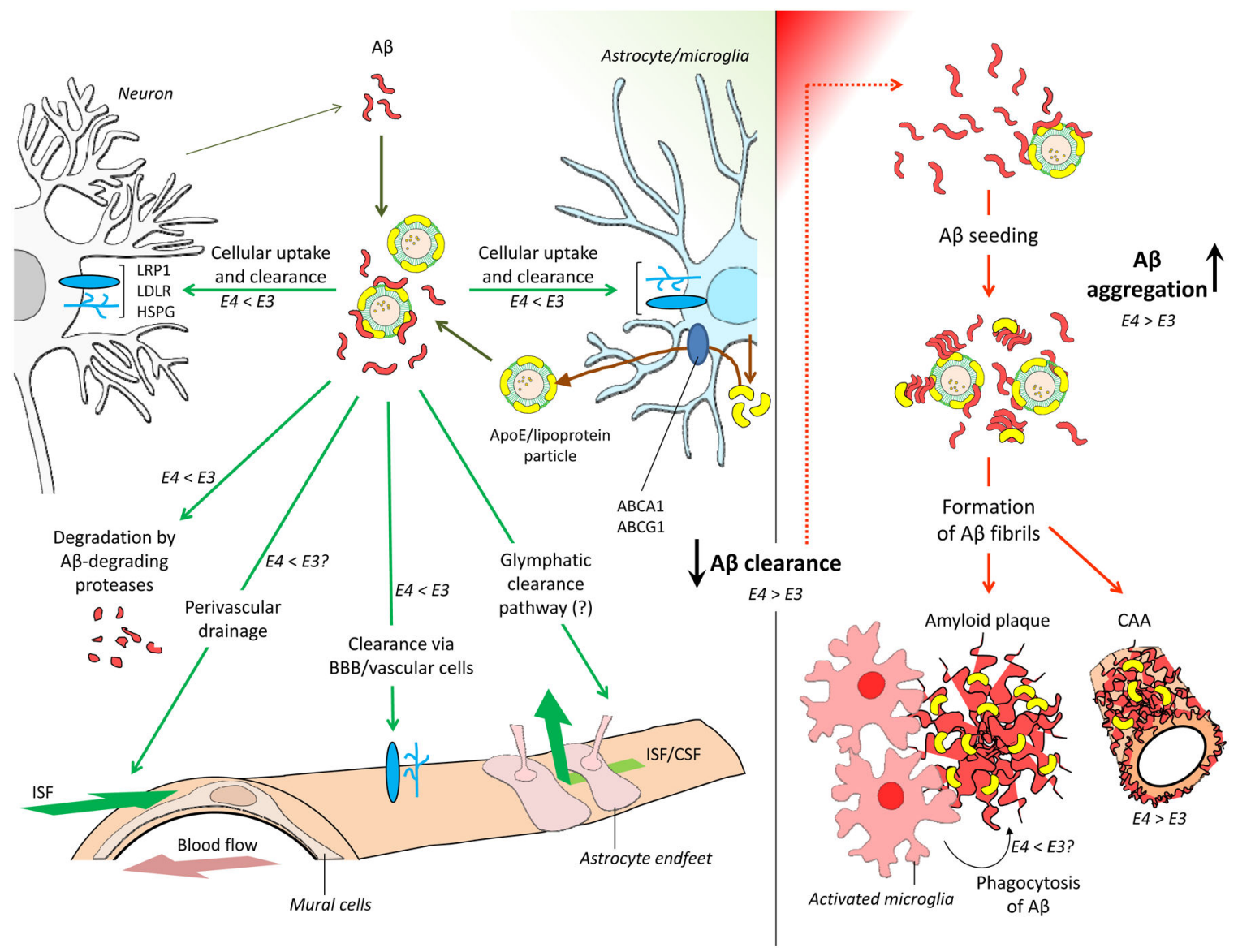

Figure 3: APOE isoforms and $A \beta$ aggregation and clearance.

a Amyloid- $\beta$ (A $\beta)$ production and clearance pathways. $A \beta$ is produced primarily in neurons through proteolytic cleavage of amyloid precursor protein (grey arrow). $A \beta$ is then removed from the brain by multiple $A \beta$ clearance pathways (green boxes), including cellular uptake and subsequent degradation, enzymatic degradation, clearance through the bloodbrain barrier (BBB), and clearance via interstitial fluid (ISF) bulk flow and, potentially, the glymphatic pathway. LDL receptor-related protein 1 (LRP1), LDL receptor (LDLR) and heparan sulfate proteoglycan (HSPG) are major APOE receptors that mediate cellular uptake of $\mathrm{A} \beta$. Apolipoprotein $\mathrm{E}$ (APOE) is produced and lipidated primarily by astrocytes (brown arrow). A sub-pool of APOE lipoprotein particles interacts with soluble A $\beta$ released into the brain interstitial fluid by neurons. $\mathbf{b} \mid$ Insufficient $A \beta$ clearance from the brain leads to $A \beta$ accumulation. This accumulation initiates $A \beta$ oligomerization and accelerates subsequent aggregation and fibrillogenesis, leading to deposition of insoluble $A \beta$ in the brain parenchyma (amyloid plaques) and in the vascular wall (cerebral amyloid angiopathy). APOE promotes the formation of $A \beta$ fibrils by accelerating the initial seeding or nucleation of $A \beta$ peptides. APOE can influence $A \beta$ clearance and aggregation, either directly or indirectly, in an isoform-dependent manner. The relative abilities of APOE3 and APOE4 to promote each pathway are indicated alongside the arrows. ABCA1, ATP-binding cassette sub-family A member 1; ABCG1, ATP-binding cassette sub-family G member 1; CSF, cerebrospinal fluid. 


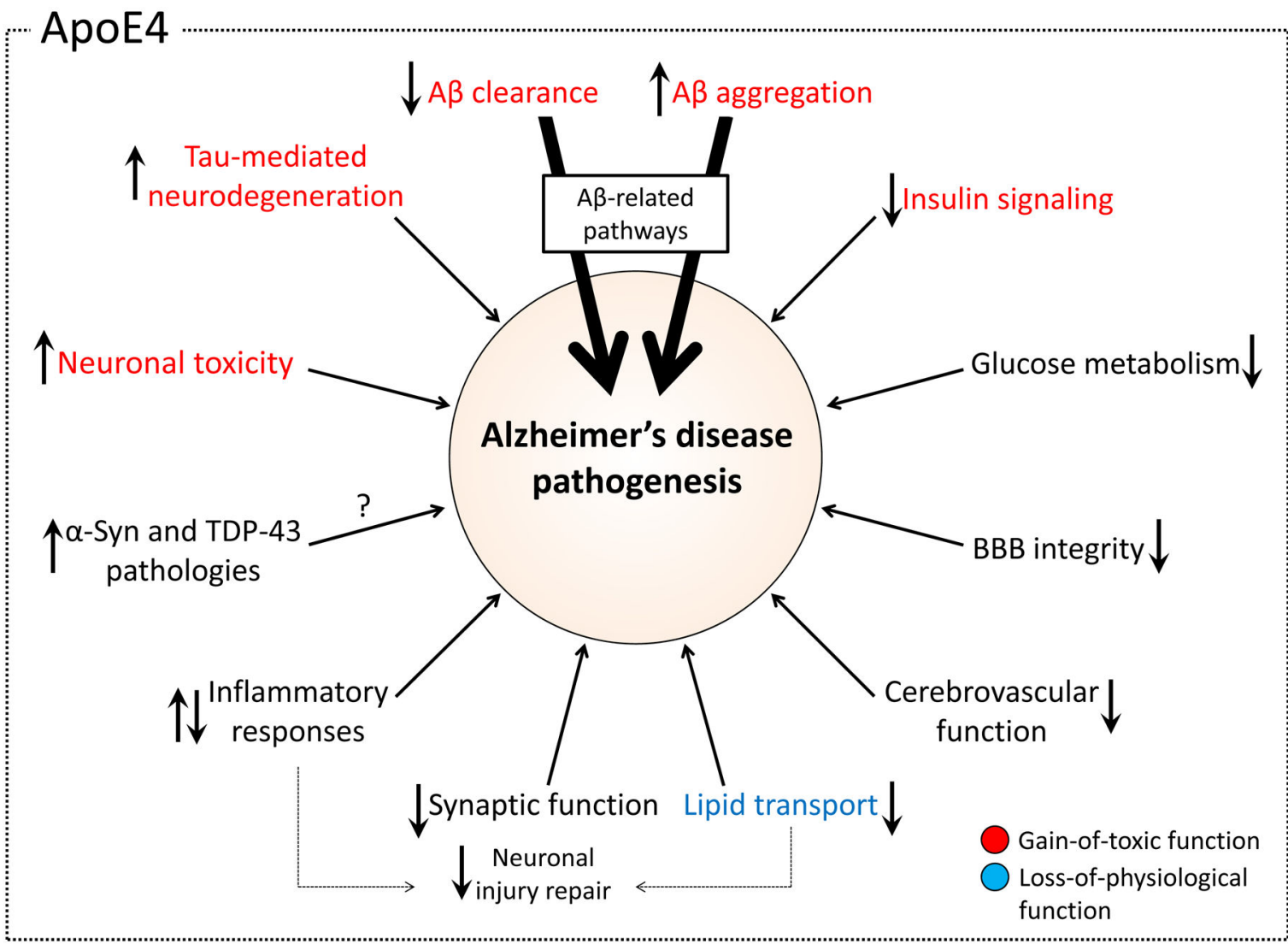

Figure 4: Effects of APOE4 on AD pathogenesis pathways.

Apolipoprotein E4 (APOE4) affects multiple different pathways in Alzheimer disease (AD) pathogenesis. Key functional pathways are shown, and the arrows within the boxes depict the effects of APOE4 compared with APOE3. Pathways are shown in red boxes if evidence suggests that APOE4 increases risk of AD via a gain of toxic function. The effects on the lipid transport pathway, shown in blue, represent a potential loss of physiological function of APOE4 relative to APOE3. Pathways shown in grey are unclassified either owing to insufficient evidence or the potential for both gain of toxic and loss of physiological function. The two thicker arrows indicate the importance of the $A \beta$-related pathway as the key mechanism by which APOE influences AD. A $\beta$, amyloid- $\beta$; $a$-syn, a-synuclein; BBB, blood-brain barrier; TDP43, TAR DNA-binding protein 43. 
Target apoE4-specific pathobiology

- APOE4 gene silencing

- Anti-apoE4 immunotherapy

- ApoE4 structure correctors

- Conversion of APOE4 to APOE3
Target pathobiology of apoE and apoE receptors

- Block apoE-A $\beta$ interaction

- Enhance receptor-mediated $A \beta$ clearance

- Reduce apoE aggregation

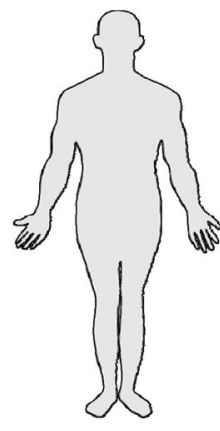

$A P O E \varepsilon 4 / \varepsilon 4$

$A P O E \varepsilon 3 / \varepsilon 4$

$A P O E \varepsilon 2 / \varepsilon 4$

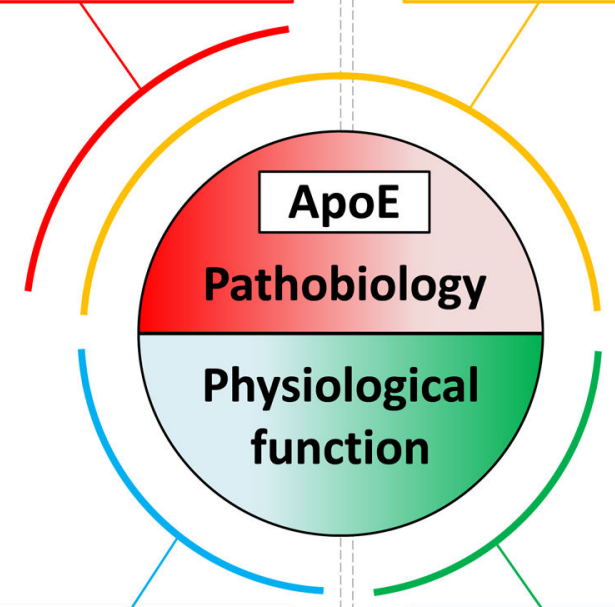

Enhance neuroprotective function of apoE2 and apoE3

- Increase apoE amount

- Increase apoE lipidation

Figure 5: Model of precision medicine based on $A P O E$ genotype.

Although all apolipoprotein E (APOE) isoforms seem to promote amyloid- $\beta$ (A $\beta$ ) deposition in the brain, the disease-driving effect is more pronounced with the presence of $A P O E^{*} \varepsilon 4$ than of $A P O E^{*} \varepsilon 2$ or $A P O E^{*} \varepsilon 3$. Therefore, a precision medicine approach in which different treatment strategies are developed for individuals with different genotypes might be beneficial. The figure lists the potential therapeutic options according to the individuals who are most likely to benefit and whether the strategy attempts to correct APOE pathobiology or restore APOE physiological function. Modulation of A $\beta$ pathology in individuals with different $A P O E$ genotypes is likely to require a combination of strategies. 
Table 1.

$A P O E$ variants and key AD-related clinical features

\begin{tabular}{|c|c|c|c|c|}
\hline $\begin{array}{l}\text { APOE } \\
\text { allelic } \\
\text { variant }\end{array}$ & $\begin{array}{l}\text { Allele } \\
\text { frequency in } \\
\text { cognitively } \\
\text { healthy } \\
\text { individuals } \\
(\%)^{286}\end{array}$ & $\begin{array}{l}\text { Allele } \\
\text { frequency } \\
\text { in patients } \\
\text { with AD } \\
(\%)^{286}\end{array}$ & $\begin{array}{l}\text { Odds ratio for } \\
\text { AD } \\
\text { development }^{286}\end{array}$ & Key clinical features \\
\hline$A P O E^{*} \varepsilon 2$ & 7 & 4 & 0.621 & $\begin{array}{l}\text { - } \\
\text { - } \\
\text { Associated with a reduced risk of } \mathrm{AD}^{6-9} \\
\text { even after adjustment for amyloid- } \beta \text { pathologies } \\
\text { - } \\
\text { Associated with an increased risk of cerebral amyloid } \\
\text { angiopathy (CAA) and CAA-related intracerebral } \\
\text { haemorrhage } \\
\text { - } \\
\text { Contributes to the onset of type III } \\
\text { hyperlipoproteinaemia }{ }^{22,56} \\
\text { Associated with increased tau pathology in progressive } \\
\text { supranuclear palsy }{ }^{122}\end{array}$ \\
\hline$\left.A P O E^{*} \varepsilon\right\}$ & 79 & 58 & 1.000 & $\begin{array}{l}\text { - } \quad \text { The most common } A P O E \text { allele } \\
\text { - } \quad A P O E^{*} \varepsilon 3 / \varepsilon 3 \text { is considered to be a reference genotype in } \\
\text { most studies }\end{array}$ \\
\hline$A P O E^{*} \varepsilon 4$ & 14 & 38 & 3.680 & 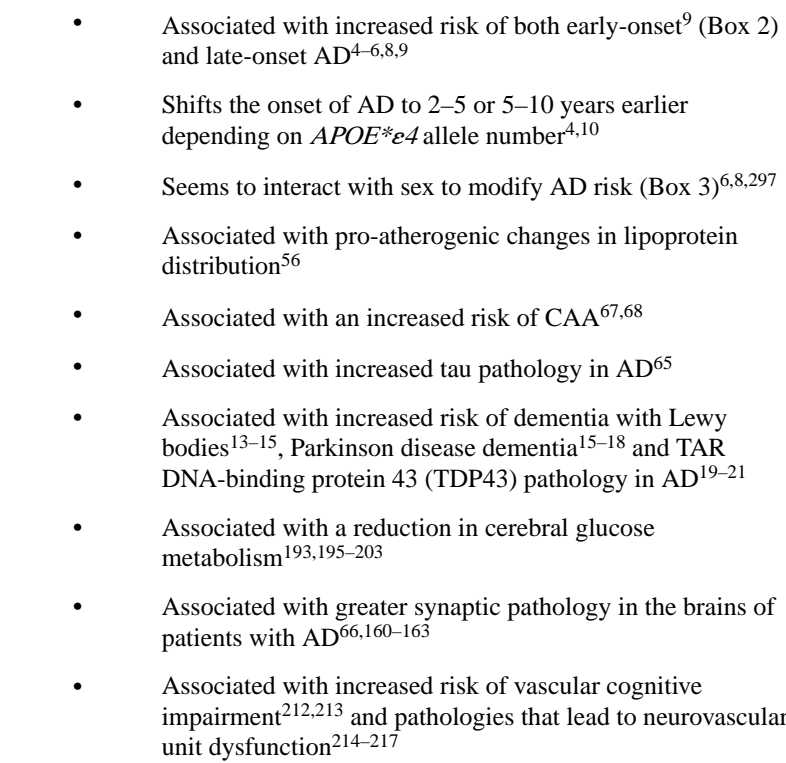 \\
\hline
\end{tabular}

$\mathrm{AD}$, Alzheimer disease; $A P O E$, apolipoprotein E. 
Table 2.

APOE genotype, $\mathrm{AD}$ risk and amyloid- $\beta$ deposition

\begin{tabular}{|c|c|c|c|c|c|}
\hline \multirow{2}{*}{$A P O E$ genotype } & \multirow{2}{*}{$\begin{array}{l}\text { Frequency in } \\
\text { cognitively healthy } \\
\text { individuals }(\%)^{286}\end{array}$} & \multirow{2}{*}{$\begin{array}{l}\text { Frequency in } \\
\text { patients with AD } \\
(\%)^{286}\end{array}$} & \multirow{2}{*}{$\begin{array}{l}\text { Odds ratio for } \mathrm{AD} \\
\text { development }^{9}\end{array}$} & \multicolumn{2}{|c|}{$\begin{array}{l}\text { Odds ratio for amyloid positivity at } 70 \text { years } \\
\text { of age } \text { a }^{85}\end{array}$} \\
\hline & & & & Cognitively healthy & $\begin{array}{l}\text { Mild cognitive } \\
\text { impairment }\end{array}$ \\
\hline$\varepsilon 2 / \varepsilon 2$ & 0.7 & 0.3 & 0.56 & NA & NA \\
\hline$\varepsilon 2 / \varepsilon 3$ & 11.0 & 4.6 & 0.56 & 0.34 & 0.59 \\
\hline$\varepsilon 3 / \varepsilon 3$ & 62.3 & 34.3 & 1.00 & 1.00 & 1.00 \\
\hline$\varepsilon 2 / \varepsilon 4$ & 1.9 & 2.6 & 2.64 & 4.29 & 2.38 \\
\hline$\varepsilon 3 / \varepsilon 4$ & 22.2 & 43.4 & 3.63 & 2.94 & 3.52 \\
\hline$\varepsilon 4 / \varepsilon 4$ & 1.9 & 14.8 & 14.49 & 18.76 & 14.50 \\
\hline
\end{tabular}

Carrying one or two apolipoprotein E $\varepsilon 4\left(A P O E^{*} \varepsilon 4\right)$ alleles increases the odds ratio for Alzheimer disease (AD) development 3-4-fold or 9-15fold, respectively, regardless of the presence of $A P O E^{*} \varepsilon 2$ or $A P O E^{*} \varepsilon 3^{6,8,9}$. The pattern of estimated probabilities of amyloid positivity for the different $A P O E$ genotypes 85 is similar to that of the risk of AD. NA, not available. 